\title{
Neurosteroids are reduced in diabetic neuropathy and may be associated with the development of neuropathic pain
}

\section{[version 1; peer review: 1 approved, 2 approved with}

\section{reservations]}

\author{
Stephen R. Humble (iD)
}

Department of Anaesthetics and Pain Management, Charing Cross Hospital, Imperial College NHS Healthcare Trust London, London, W6 8RF, UK

V1 First published: 05 Aug 2016, 5:1923

https://doi.org/10.12688/f1000research.9034.1

Latest published: 05 Aug 2016, 5:1923

https://doi.org/10.12688/f1000research.9034.1

\section{Abstract}

Introduction: Peripheral and central sensitisation are implicated in the development of neuropathic pain. Hypersensitivity of pain pathway neurons has been described in animal models of diabetic neuropathy, which is postulated to be related to an imbalance between inhibitory and excitatory signals within the spinal cord. GABAergic neurons within the pain pathway are vital for the transmission of painful stimuli to higher centres. A developmental change in the rate of exponential decay of GABAergic synaptic events has been observed in other types of neurons and this may be associated with fluctuations in endogenous neurosteroid tone.

Methods: The whole-cell patch-clamp technique was used on slices of neural tissue. Electrophysiological recordings were obtained from wild type mice between the ages of 6 and 80 days in the spinal cord, the nucleus reticularis of the thalamus and the cerebral cortex. Recordings were also obtained from mice with diabetic neuropathy (ob/ob and $\mathrm{db} / \mathrm{db}$ ) between the ages of 60 and 80 days. Behavioural experiments were performed to examine mechanical and thermal nociception.

Results: Electrophysiological recordings from cortical pain pathway neurons from mature type-2 diabetic mice revealed that the endogenous neurosteroid tone is reduced compared to control. However, selected neurosteroid compounds had a more pronounced effect on the $\mathrm{GABA}_{A}$ receptors of these diabetic mice. ob/ob mice exhibit mechanical hyperalgesia and allodynia, which was reduced by neurosteroids applied exogenously.

Conclusions: The reduced endogenous neurosteroid tone in ob/ob

\begin{tabular}{|c|c|c|c|}
\hline \multicolumn{4}{|c|}{ Open Peer Review } \\
\hline \multicolumn{4}{|c|}{ Approval Status ? ? } \\
\hline & 1 & 2 & 3 \\
\hline version 1 & $?$ & $\checkmark$ & $?$ \\
\hline 05 Aug 2016 & view & view & view \\
\hline
\end{tabular}

1. Christopher Connolly, University of Dundee, Dundee, UK

2. Anthony H. Dickenson, University College London, London, UK

3. Xue-Jun Song, Peking University Cancer Hospital and Institute, Beijing, China

Changyu Jiang, Nanshan Hospital, Guangdong, Shenzhen, China

Any reports and responses or comments on the article can be found at the end of the article. 
mice may be linked to their hypersensitivity. Neurosteroids may exert analgesic effects in pathological pain states by attempting to restore the physiological GABAergic inhibitory tone.

\section{Keywords}

Neuropathic pain, Neurosteroids, diabetes, neuropathy, GABAAR, GABAA receptor, ob ob, db db

Corresponding author: Stephen R. Humble (stephen.humble@imperial.nhs.uk)

Competing interests: No competing interests were disclosed.

Grant information: This research was supported by the Wellcome Trust (Grant No. 090667).

The funders had no role in study design, data collection and analysis, decision to publish, or preparation of the manuscript.

Copyright: $\odot 2016$ Humble SR. This is an open access article distributed under the terms of the Creative Commons Attribution License, which permits unrestricted use, distribution, and reproduction in any medium, provided the original work is properly cited.

How to cite this article: Humble SR. Neurosteroids are reduced in diabetic neuropathy and may be associated with the development of neuropathic pain [version 1; peer review: 1 approved, 2 approved with reservations] F1000Research 2016, 5:1923 https://doi.org/10.12688/f1000research.9034.1

First published: 05 Aug 2016, 5:1923 https://doi.org/10.12688/f1000research.9034.1 


\section{Text box}

\section{What's already known about this topic?}

- There is a worldwide obesity diabetes epidemic, causing a huge amount of morbidity including neuropathy and neuropathic pain.

- The mechanisms responsible for the development of neuropathy and neuropathic pain are not well understood.

- Peripheral and central sensitisation are implicated in the development of neuropathic pain with neuroplastic changes occurring at multiple levels of the pain pathway.

- Hypersensitivity of pain pathway neurons has been described in animal models of diabetic neuropathy, which is postulated to be related to an imbalance between inhibitory and excitatory signals within the spinal cord. GABAergic neurons within the pain pathway are vital for the transmission of painful stimuli to higher centres involved in the perception of pain.

- GABA receptors are an important target for many drugs, and specific endogenous neurosteroids act as potent allosteric modulators of these receptors.

- A developmental change in the rate of exponential decay of GABAergic synaptic events has been observed in other types of neurons and this may be associated with fluctuations in endogenous neurosteroid tone.

\section{What does this study add?}

- This paper explores potential underlying mechanisms and identifies potential therapeutic targets in order to promote translational work in this field.

- This is the first electrophysiological GABA receptor characterisation of two models of type-2 diabetes mellitus and reports the discovery of a reduced endogenous GABA-ergic neurosteroid tone that may mediate painful neuropathic hypersensitivity.

- The paper then reports the anti-nociceptive impact of neurosteroids on live mice, thus complementing the electrophysiological data.

- These discoveries may ultimately lead to a new rational avenue of research aimed at understanding and treating painful diabetic neuropathy and the neuropathic mechanisms may be analogous in other neuropathic conditions such as chemotherapyinduced neuropathic pain.

\section{Introduction}

A loss of physiological inhibitory tone is associated with hypersensitivity to painful stimuli such as allodynia and hyperalgesia (Chen \& Pan, 2002; Zeilhofer, 2008). The GABA A receptor $\left(\mathrm{GABA}_{\mathrm{A}} \mathrm{R}\right)$ is the major inhibitory receptor in the mammalian nervous system and mediates inhibitory tone throughout the pain pathway (D'Hulst et al., 2009; Johnston, 2005). Reduced GABAergic inhibition within the spinal cord may be implicated in the development of hypersensitivity to nociceptive stimuli (Munro et al., 2009; von Hehn et al., 2012; Zeilhofer, 2008).
Therefore, pharmacological agents that enhance $\mathrm{GABA}_{\mathrm{A}} \mathrm{R}$ function could be useful to counteract lost inhibitory tone (Knabl et al., 2008; Munro et al., 2009). Neurosteroids such as allopregnanolone are potent allosteric modulators of this receptor (Callachan et al., 1987; Hosie et al., 2006; Figure 1). Indeed, an upregulation in the production of endogenous neurosteroids within the spinal cord in response to peripheral inflammation has been shown to have an analgesic effect. The analgesic effect could be suppressed by the administration of finasteride to inhibit the enzyme $5 \alpha-\mathrm{R}$, which converts progesterone to its more active metabolites (Poisbeau et al., 2005; Schlichter et al., 2006).

There is a burgeoning obesity and type-2 diabetes epidemic worldwide and the incidence is likely to become even greater (Danaei et al., 2011). Neurosteroids such as progesterone have been studied for their potentially protective effects for a number of different neuropathologies including stroke, brain and spinal injuries (Mensah-Nyagan et al., 2009; Stein, 2008). It is possible that fluctuations in endogenous neurosteroid levels may have a pathophysiological role in the development of diabetic neuropathic pain. In mice, diabetic neuropathy develops over weeks, which allows disease progression and the efficacy of interventions to be studied within a relatively a short timeframe (Cefalu, 2006; Kaplan \& Wagner, 2006). The type-2 diabetic ob/ob mouse, which has an autosomal recessive nonsense mutation on chromosome 6 causing leptin deficiency develops morbid obesity due to its rapacious appetite and exhibits a predictable and spontaneous neuropathic phenotype (Drel et al., 2006; Latham et al., 2009; Lindstrom, 2007; Vareniuk et al., 2007). In contrast, the $d b / d b$ mouse has an autosomal recessive mutation of the leptin receptor gene, which prevents leptin from activating its receptor (Chen et al., 1996; Chung et al., 1996).

Pain has sensory, emotional and cognitive components and therefore multiple areas within the cerebral cortex are involved in generating the experience of pain (Flor \& Bushnell, 2005; Treede et al., 1999). Areas such as the insular, somatosensory, anterior cingulate and prefrontal cortices and the thalamus may be considered as a 'pain matrix.' The cerebral cortex is organised into parallel mini-columns of synaptically linked neurons that span part, or all of the six horizontal cortical layers. Mini-columns may be clustered together to constitute functional modules (Lubke \& Feldmeyer, 2007; Mountcastle, 1997). GABAergic inhibitory interneurons are present in all layers of the cortex but are most abundant in layers 2/3 and lower in layer 4 (Meyer et al., 2011). By improving the understanding at the molecular level it may be possible to identify novel therapeutic targets for painful diabetic neuropathy.

\section{Methods}

Breeding and housing of mice

All procedures were carried out in compliance with the University of Dundee code of practice following consideration by the University Research Ethics Committee (UREC) and in accordance with Schedule 1 of the Animals (Scientific Procedures) Act 1986 (UK). Home Office Project Licence numbers: PPL 60/4144 and PPL 60/4005. Wellcome Trust Grant number 090667. Wild Type (WT) mice aged less than 2 months were obtained from an in-house colony. C57/B16J WT mice aged 2 months were purchased from Charles River, UK while OlaHSD $o b / o b$ mice, $d b / d b$ mice and their respective strain-matched WT littermates, all aged 


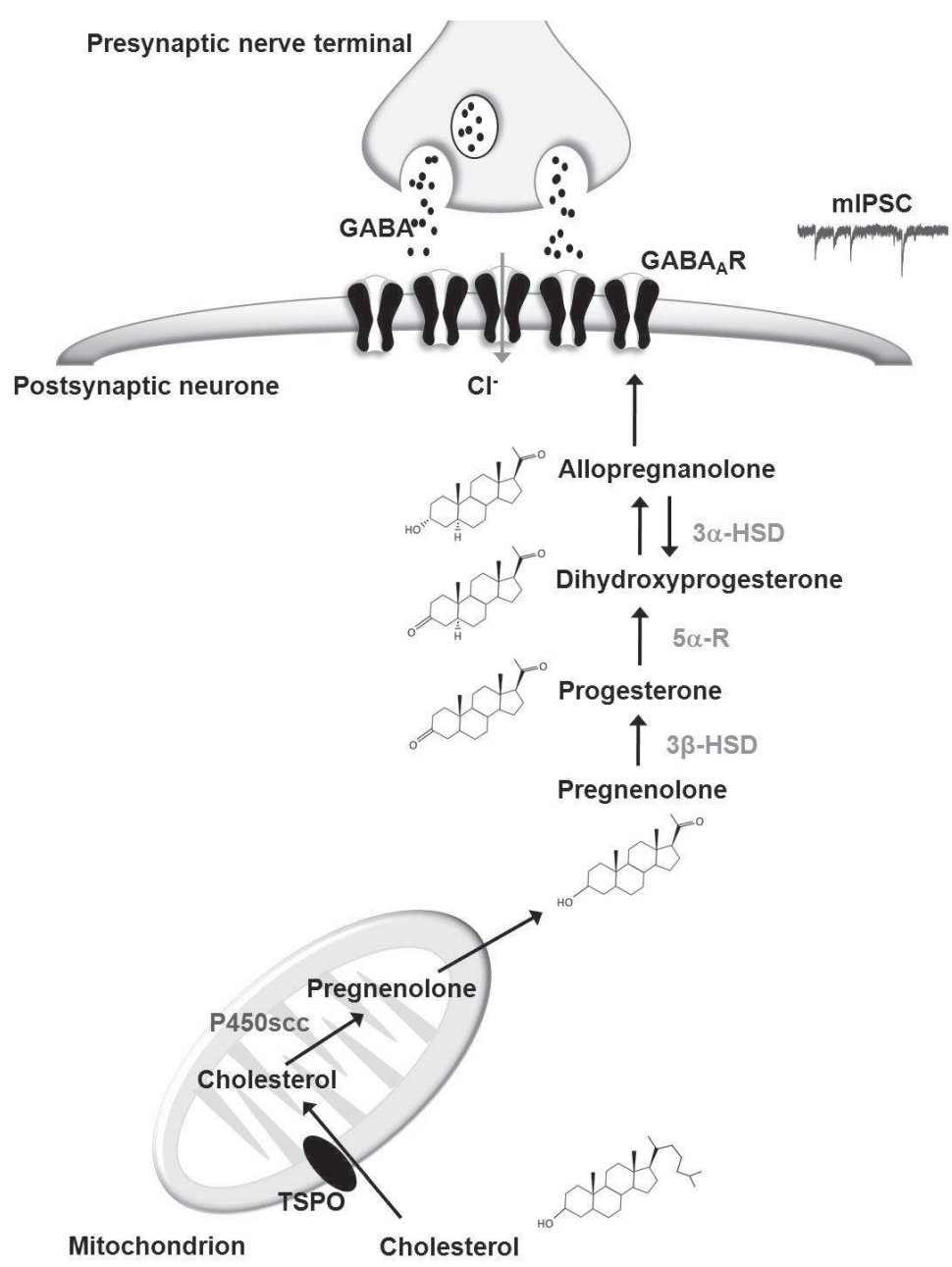

Figure 1. Modulation of the GABA $\mathbf{R}$ by endogenous neurosteroids. Cholesterol is taken through the mitochondrial membrane by the translocator protein where it is converted to pregnenolone by the cytochrome P450 side chain cleavage enzyme. Pregnenolone undergoes stepwise enzymatic conversion to other neurosteroid compounds and ultimately allopregnanolone which modulates GABA R function. Neurosteroids may act via paracrine or autocrine mechanisms. Postsynaptic GABA ${ }_{A}$ Rs are activated by GABA that has been released from vesicles in the presynaptic nerve terminal. GABA induces a conformational change in the $\mathrm{GABA}_{A} R$, which 'opens' its central pore, allowing the passage of chloride ions. The negatively charged chloride ions typically induce hyperpolarisation of the neuronal membrane, which is associated with neuronal inhibition. Neurosteroids such as allopregnanolone enhance GABA $R$ function and therefore facilitate neural inhibition.

2 months were purchased from Harlan UK and housed in the same in-house colony. All animals were male and were kept under an alternating $12 \mathrm{hr}$ light/dark cycle and had ad libitum access to food and water.

\section{Spinal cord dissection technique}

Prior to dissection mice were killed instantly by cervical dislocation (Schedule 1), the tissue was then submerged immediately into a bath of ice-cold oxygenated $\left(95 \% \mathrm{O}_{2} / 5 \% \mathrm{CO}_{2}\right)$ artificial cerebrospinal fluid (aCSF). The aCSF comprised: $225 \mathrm{mM}$ sucrose, $10 \mathrm{mM}$ glucose, $10 \mathrm{mM} \mathrm{MgSO}_{4}, 26 \mathrm{mM} \mathrm{NaHCO}, 1.25 \mathrm{mM} \mathrm{NaH}_{2} \mathrm{PO}_{4}$, $2.5 \mathrm{mM} \mathrm{KCl}, 0.5 \mathrm{mM} \mathrm{CaCl}, 1 \mathrm{mM}$ ascorbic acid and $3 \mathrm{mM}$ pyruvic acid (total osmolarity $\sim 330 \mathrm{mosm} / \mathrm{l}$ ). The spinal cord was extracted by anterior laminectomy as per Keller et al. (2001). The cord was immediately set within agar gel, which was glued to the Leica VT1000S vibratome (Heidelberg, Germany) for slicing. Horizontal, thoracolumbar slices, $(300-350 \mu \mathrm{m})$ were cut and transferred onto a nylon mesh platform within a storage chamber containing oxygenated $\left(95 \% \mathrm{O}_{2} / 5 \% \mathrm{CO}_{2}\right)$ artificial extracellular solution (aECS) comprising: $126 \mathrm{mM} \mathrm{NaCl}, 10 \mathrm{mM}$ glucose, $2 \mathrm{mM} \mathrm{MgCl}$, $26 \mathrm{mM} \mathrm{NaHCO}, 1.25 \mathrm{mM} \mathrm{NaH} \mathrm{PO}_{4}, 2.95 \mathrm{mM} \mathrm{KCl}, 2 \mathrm{mM} \mathrm{CaCl}$, $1 \mathrm{mM}$ ascorbic acid, $3 \mathrm{mM}$ pyruvic acid and $2 \mathrm{mM}$ kynurenic acid (Total measured osmolarity $\sim 310 \mathrm{mOsm} / 1$ ). Slices were stored at room temperature for at least one hour before being used to obtain electrophysiological recordings.

\section{Brain slicing technique}

Brain tissue was also obtained following the cervical dislocation method (Schedule 1) and submerged in aCSF as above. For all nucleus reticularis (nRT) preparations the aCSF solution was the same as that described above for spinal cord but the sucrose concentration was increased to $234 \mathrm{mM}$ giving a total osmolarity 
of $\sim 340 \mathrm{mOsm} / 1$ as this improved the condition of the slices. For cortical preparations in mice below 2 months of age the aCSF was the same as for the spinal cord. Neuronal viability deteriorates with increasing age and for mice above the age of 2 months, including all $o b / o b$ and $d b / d b$, a different solution was required to optimise the condition of the slices as previously described by Maguire et al. (2014). This consisted of 140mM potassium gluconate, $10 \mathrm{mM}$ HEPES, $15 \mathrm{mM}$ sodium gluconate, $0.2 \mathrm{mM}$ EGTA, $4 \mathrm{mM} \mathrm{NaCl}, 1 \mathrm{mM}$ ascorbic acid and $3 \mathrm{mM}$ pyruvic acid. Sodium hydroxide solution was then added to bring the $\mathrm{pH}$ up to 7.2. The brain was removed carefully from the skull and slices were obtained using a Vibratome series 1000 PLUS Sectioning System (Intracell, Royston, Hertfordshire, UK). Cortical slices were cut in the coronal plane and nRT slices in the horizontal plane. Slice thickness was greatest for the youngest mice and least for the oldest mice $(250-350 \mu \mathrm{M})$. Slices were transferred immediately to a storage chamber as previously described.

\section{Electrophysiology}

Subsequently, the slices were transferred to a recording chamber under an Olympus BX51WI fixed-stage upright microscope. An infrared differential interference contrast disc and a water immersion objective $(\times 40)$ were used for visualisation of neurons within the dorsal horn of the spinal cord, the nucleus reticularis of the thalamus and the somatosensory area of the cortex respectively. The chamber was perfused continuously with oxygenated artificial extracellular solution (aECS). Slices were held in position using a small grid. Whole-cell patch-clamp recordings were obtained using an Axopatch 200B amplifier and all recordings were made at a holding potential of $-60 \mathrm{mV}$ and at a temperature of $35^{\circ} \mathrm{C}$. The extracellular solution contained kynurenic acid $(2 \mathrm{mM})$, strychnine $(0.5 \mu \mathrm{M})$ and tetrodotoxin $(0.5 \mu \mathrm{M})$ to antagonise ionotropic glutamate, glycine receptors and voltage-gated sodium channels respectively. Patch electrodes were prepared from thick walled borosilicate glass capillaries (Garner Glass Co., Claremont, CA, USA). Such electrodes had an open-tip resistance of $\sim 4 \mathrm{M} \Omega$ when filled with intracellular solution containing: $135 \mathrm{mM} \mathrm{CsCl}, 10 \mathrm{mM}$ HEPES, 10mM EGTA, $1 \mathrm{mM} \mathrm{CaCl}{ }_{2}, 1 \mathrm{mM} \mathrm{MgCl}{ }_{2}, 2 \mathrm{mM} \mathrm{Mg-ATP,}$ $5 \mathrm{mM}$ QX-314, $\mathrm{pH} 7.2$, titrated with $\mathrm{CsOH}$. The measured osmolarity was $310 \mathrm{mOsmol} / \mathrm{l}$. Typically, the mean whole-cell capacitance was $5-15 p$ F. Series resistance was compensated for by up to $80 \%$ and recordings were considered invalid where the series resistance changed by more than $20 \%$ or if it exceeded $15 \mathrm{M} \Omega$. A $2 \mathrm{kHz}$ frequency filter was used for all recordings and analysis of each cell was performed offline.

\section{Data analysis}

The Strathclyde Electrophysiology Software, WinEDR and WinWCP, (Dr J Dempster, University of Strathclyde, Glasgow, UK) was used for the analysis of recordings. Only recordings that met specific quality criteria were included in the analysis. Using an algorithmic detection protocol, miniature inhibitory postsynaptic currents (mIPSCs) were detected with an amplitude threshold of at least $-5 \mathrm{pA}$ and duration $>2 \mathrm{~ms}$. Each individual mIPSC was then inspected visually to ensure validity and exclude artifactual events. mIPSCs with a rise time of more than $1 \mathrm{~ms}$ were excluded to prevent the inclusion of events originating from a distal source. At least 50 events were sought for each recording, and the average peak amplitude, rise time (10-90\%), charge transfer (area under the curve) and $\mathrm{T}_{70}$ (time required to decay by $70 \%$ ), were analysed. The
mIPSCs were digitally averaged by alignment at the midpoint of the rising phase. The mIPSC decay was fitted by monexponential $\left(y(t)=A e^{-t / \tau}\right)$ and biexponential $\left(\mathrm{y}(\mathrm{t})=\mathrm{A}_{\text {fast }} \mathrm{e}^{(-t / \tau \text { fast })}+\mathrm{A}_{\text {slow }} \mathrm{e}^{(-\mathrm{t} / / \mathrm{slow})}\right)$ functions to determine which one was more appropriate ( $A$ is amplitude, $t$ is time and $\tau$ is the decay time constant). The standard deviations of the residuals of the monexponential and biexponential functions were measured and an $F$ test applied. For the vast majority of mIPSCs analysed, the decay was best described by a biexponential function. Consequently, a mean weighted decay constant $\left(\tau_{\mathrm{w}}\right)$ was calculated to determine the relative contribution of each decay component. $\tau_{\mathrm{w}}$ is a mathematical constant generated by considering the fast initial component of biexponential decay $\tau_{1}$ and the later slower component $\tau_{2}$. The value of $\tau_{\mathrm{w}}$ is determined for the mean mIPSC for each cell by determining the relative proportion that $\tau_{1}$ and $\tau_{2}$ contribute to the biexponential decay. The following equation was used: $\tau_{\mathrm{w}}=\tau_{\text {fast }} \mathrm{P}_{1}+\tau_{\text {slow }} \mathrm{P}_{2}$, where $\mathrm{P}_{1}$ and $\mathrm{P}_{2}$ represent the proportions of the synaptic current decay curve described by each component.

\section{Drug and solution preparation and administration}

Salts used in the preparation of aECS and aCSF solutions were purchased from VWR (West Chester, Pennsylvania, USA). Strychnine (Sigma Chemicals, St. Louis, MO, USA), tetrodotoxin (Tocris, Bristol, UK) and bicuculline (Axxora, Nottingham, UK) and THIP (generous gift from B Ebert) were prepared as concentrated stock solutions in double-filtered water to be added to the aECS. Other compounds such as progesterone, ganaxolone, allopregnanolone, dihydroxy-progesterone, provera, indometacin, finasteride were purchased from Tocris or Sigma and prepared as concentrated stock solutions in dimethyl sulfoxide (DMSO). The cyclodextrins (CDs; Sigma) were dissolved directly into the aECS, or the intracellular solution. Brain and spinal cord slices were placed under the microscope into a transparent plastic chamber filled with aECS. The aECS was perfused through the chamber using a rate-adjustable gravity-based system consisting of hard plastic tubing that connected an oxygenated reservoir to the chamber. Simultaneously, a peristaltic pump system (Minipuls 3, Gilson, UK) drained the aECS from the opposite side of the chamber and recycled it back to the reservoir. The fluid-filled circuit also ran through a custom made heating system (G23, UCL, London, UK) controlled by a temperature monitoring system (School of Pharmacology, London, UK) that maintained the near physiological temperature of $35^{\circ} \mathrm{C}$ throughout.

\section{Behavioural experiments}

Drug administration. The drug, or vehicle, was administered by intra-peritoneal injection using a fine $1 \mathrm{ml}$ syringe and experiments were made pre- and post- injection in a randomised and blinded manner. Neurosteroids are lipophilic and have very limited solubility in aqueous solution, but can be solubilised in $0.9 \%$ saline using 2-hydroxy propyl $\beta$-cyclodextrin $(\beta-C D)$ to facilitate administration (Besheer et al., 2010; Carter et al., 1997; Reddy \& Rogawski, 2010). Neurosteroids were therefore administered in $40 \% \beta-C D$ solution.

Rotarod test. The rotarod test comprises an elevated rotating cylinder upon which a rodent is placed (Jones \& Roberts, 1968; Pritchett \& Mulder, 2003). In order to avoid falling off the rotarod, the mouse must maintain constant motion; hence it is a test of forced motor activity (Jones \& Roberts, 1968; 
Pritchett \& Mulder, 2003). To remain on the rotarod while it accelerates at a set rate the mouse requires balance and coordination. Mice were placed on the rotarod and the accelerating rotarod protocol was used. Specifically, the rod starts to rotate at 6 revolutions per minute (rpm) and is then increased in $4 \mathrm{rpm}$ increments up to a maximum of $50 \mathrm{rpm}$. The experiment continues until the mouse falls off, or until the cut-off time of 300 seconds has elapsed.

Thermal nociception. A modified tail flick test (D'Armour \& Smith, 1941; Mogil, 2009) was employed as follows: Thermal nociceptive thresholds were assessed by the immersion of $2 \mathrm{~cm}$ of the animal's tail in a water bath maintained at a specified temperature such as $40-50^{\circ} \mathrm{C}$ until the tail flick manoeuvre was initiated. The tail flick latency time was recorded and this parameter was used to compare the effect of neurosteroids versus injection of control vehicle and baseline measurements. A cut off time of 15 seconds was used to minimise the likelihood of tissue damage. The results of each experiment may be expressed in seconds, or as a percentage of the maximum possible effect (MPE) i.e. a percentage of 15 seconds.

Mechanical nociception. A series of calibrated von Frey filaments (Ugo Basile, It) were employed to characterise mechanical nociceptive thresholds in WT and $o b / o b$ mice. The mice were placed into clear plastic cubicles on top of a raised platform (Ugo Basile, Italy) with a meshed surface and allowed to acclimatise to the new environment for 30 minutes. The tip of the von Frey filament was pressed carefully onto the middle of the ventral ('palmar') surface of the hindpaw. Sufficient force to induce bending of the shaft of the filament was applied for up to 5 seconds and the presence of a withdrawal response noted if it occurred. The procedure was repeated until each hindpaw had received five presses of the filament. Only robust and immediate withdrawal responses were considered as positive. Each mouse could have a maximum score of 10 (five for each hindpaw). Testing would commence with the thinnest filament used and then progress to thicker filaments. Pilot studies were carried out to determine the optimal four filaments to be used in the mice: $0.16 \mathrm{~g}, 0.4 \mathrm{~g}, 0.6 \mathrm{~g}$ and $1 \mathrm{~g}$ filaments. They elicited a response in approximately $20 \%, 40 \%, 60 \%$ and $90 \%$ of occasions when applied to adult WT mice. This meant that these filaments could be used to test for the presence of mechanical hypersensitivty and nociception in the $o b / o b$ mouse. This method was adapted from work published in rats with neuropathic sensitisation (Meyer et al., 2011).

Statistical analysis. All data in the results section are expressed as the arithmetic mean \pm the standard deviation (SD). The following statistical tests were employed where appropriate for the electrophysiological data: Student's t test (Excel, Microsoft Office), One-way ANOVA, One-way and Two-way RM ANOVA (Sigmastat). The following non-parametric statistical tests were employed for the behavioural data: Mann-Whitney Rank Sum test, Kruskal Wallis one-way ANOVA on ranks and the Wilcoxon signed rank test (before \& after; Sigmastat).

\section{Results}

The decay time of $\mathrm{GABA}_{A} \mathrm{R}$ mIPSCs decreases with development at three levels of the pain pathway

Electrophysiological recordings were made from C57/B16 mice in lamina II (LII) of the dorsal horn of the spinal cord, the nucleus reticularis (nRT) of the thalamus and layer $2 / 3$ of the cortex (pyramidal neurons). These neurons were selected due to their modulatory role in nociceptive transmission, associated with the perception of pain in humans (Clasca et al., 2012; Cox et al., 1997; DeFelipe \& Farinas, 1992; Gentet \& Ulrich, 2003). Previous work (Brown et al., 2015) on murine neurons of the cortex and thalamocortical neurons of the ventrobasal (VB) thalamus revealed that fluctuations in the endogenous neurosteroid tone during development (P7-P24) influenced the duration of miniature inhibitory postsynaptic currents (mIPSCs).

Previous studies of LII neurons revealed the mIPSC time course of decay may reduce with development, a perturbation that may be caused by the loss of an endogenous steroid tone (Keller et al., 2001; Keller et al., 2004; Maguire et al., 2014; Rajalu et al., 2009). mIPSC decay $\left(\tau_{\mathrm{W}}\right)$ decreased with development $(\mathrm{P} 8-11=$ $24.8 \pm 2 \mathrm{~ms} ; \mathrm{n}=26 ; \mathrm{P} 17-25=19.4 \pm 1.8 \mathrm{~ms}, \mathrm{n}=31 ; \mathrm{P} 60-75=$ $17.5 \pm 1.8 \mathrm{~ms}, \mathrm{n}=13$; One-way ANOVA, $P<0.05$; Figure $2 \mathrm{~A}, \mathrm{~B}$ ). The $\tau_{\mathrm{W}}$ is approximately equivalent to the time taken for the mIPSC to decrease by $67 \%$ from the peak amplitude. The unfavourable signal-to-noise of individual mIPSCs precludes the accurate fitting of the $\tau_{\mathrm{w}}$ to individual mIPSCs. Therefore, this function is fitted to the mean mIPSC derived for each neuron.

The nRT is the main source of GABAergic input into the thalamus and there are reciprocal GABAergic loops of innervation between nRT neurons and those of the VB. The two types of neurons, nRT and VB; regulate each other's function by this mutual inhibitory mechanism (Arcelli et al., 1997; Cox et al., 1997; Gentet \& Ulrich, 2003; Guillery \& Harting, 2003). The inter-relationship between the nRT and VB acts to modulate nociceptive transmission (Huh et al., 2012). Recordings from nRT neurons were made at three developmental stages: P6-7, P9-10 and P17-25. It is not practical to make such recordings from mice over the age of P25 due to the high density of axonal projections (Cox et al., 1997; Pinault \& Deschenes, 1998). The mIPSC decay $\left(\tau_{\mathrm{w}}\right)$ of $\mathrm{nRT}$ neurons decreased significantly with development $(\mathrm{P} 6-7=33.2 \pm$ $1 \mathrm{~ms}, \mathrm{n}=24$; P9-10 = $22.5 \pm 0.7 \mathrm{~ms}, \mathrm{n}=14 ; \mathrm{P} 17-25=18.2 \pm$ $0.6 \mathrm{~ms}, \mathrm{n}=32$; One-way ANOVA, $P<0.05$; post hoc Newman Keul's test revealed significant differences between all groups, $P<0.05$; Figure 2C,D).

Further experiments revealed that $\mathrm{GABA}_{\mathrm{A}} \mathrm{Rs}$ from neurons at all three levels of the pain pathway are sensitive to modulation by neurosteroids (see Additional material). The endogenous neurosteroid tone was explored using $\gamma$-cyclodextrin $(\gamma-\mathrm{CD})$, a barrelshaped molecule known to sequester neurosteroids (Shu et al., 2004; Shu et al., 2007). The three principle types of CD are the $\alpha-C D$, $\beta-C D$ and $\gamma-C D$, they have internal diameters of $5.2 \mathrm{~nm}, 6.4 \mathrm{~nm}$ and $8.3 \mathrm{~nm}$ respectively (Cooper et al., 2005; Davis \& Brewster, 2004). The largest of these, $\gamma$-CD is the most effective for the sequestration of neurosteroids (Brown et al., 2015; Shu et al., 2004; Shu et al., 2007). The mIPSC decay $\left(\tau_{\mathrm{w}}\right)$ in WT mice was significantly decreased in the presence of $\gamma-\mathrm{CD}$, but not by $\alpha-\mathrm{CD}$, or $\beta-\mathrm{CD}$ (see Additional material). $\gamma$-CD has been reported to have no direct effect on the $\mathrm{GABA}_{\mathrm{A}} \mathrm{R}$ (Shu et al., 2004; Shu et al., 2007) and neither of the smaller molecules, $\alpha-C D$ or $\beta-C D$, had an impact on mIPSC $\tau_{\mathrm{w}}$ (Table S2). Intracellular application of $\gamma$-CD via the recording pipette was found to be the optimal method of application (see Additional material) and is consistent with the hypothesis 
A

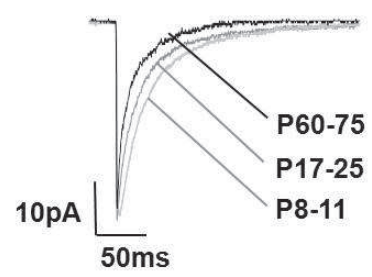

C

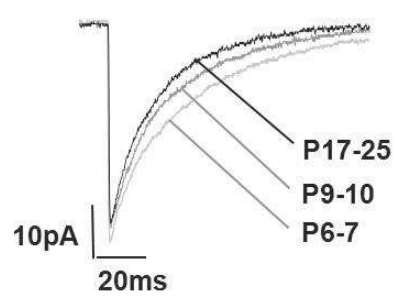

E

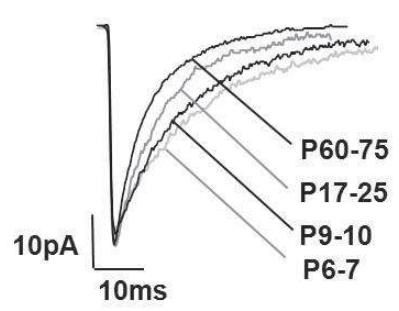

B

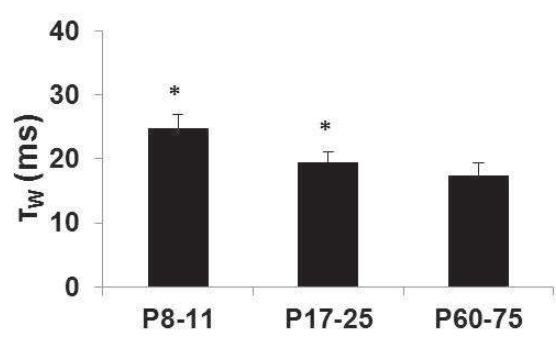

Postnatal age of LII neurones

(days)

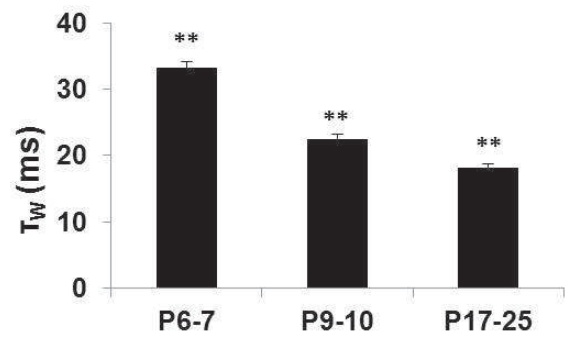

Postnatal age of $n R T$ neurones

F (days)

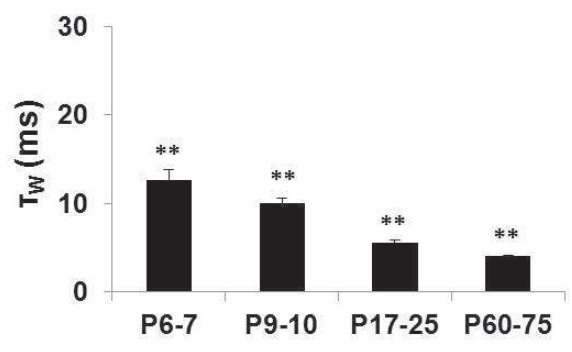

Postnatal age of cortical neurones (days)

Figure 2. The decay time of $\mathrm{GABA}_{\mathrm{A}} \mathrm{R}$ mIPSCs of neurons from three levels of the pain pathway decreases with development. (A) Superimposed exemplar GABA $A_{A}$-mediated mIPSCs recorded from representative spinal neurons from three stages of development: P8-11 (light grey), P17-25 (grey) and P60-75 (black). Note the reduction of GABA $A_{A}$ mIPSC decay time that occurs with development. (B) Histogram illustrating the shortening of GABA $R$ mIPSCs with development (One-way ANOVA * $P<0.05 ; n=13-31$ ). (C \& D) A parallel developmental change is observed in nRT neurons One-way ANOVA $P<0.05$. Post hoc Newman Keul's test revealed significant differences between all groups, $\left.{ }^{* *} P<0.05 ; \mathrm{n}=14-24\right)$. (E \& F) A parallel developmental change is observed in $\mathrm{L} 2 / 3$ cortical neurons One-way ANOVA $P<0.05$. Post hoc Newman Keul's test revealed significant differences between all groups, ${ }^{\star \star} P<0.05 ; n=7-35$ ).

that the $\mathrm{GABA}_{\mathrm{A}} \mathrm{R}$-active neurosteroids are synthesised within the pain pathway neurons themselves (Akk et al., 2005; Chisari et al., 2009; Tsutsui, 2008).

Pipette-applied $\gamma$-CD reduces decay time of $\mathrm{GABA}_{A} R$ mIPSCs of layer $2 / 3$ pyramidal cortical neurons at two stages of development

The mIPSC decay $\left(\tau_{\mathrm{w}}\right)$ of $\mathrm{L} 2 / 3$ cortical neurons at two stages of maturity (P9-10 and P60-75) was significantly decreased in the presence of intracellular $\gamma$-CD $(P<0.05$, Table S1). These data are in contrast to the lack of effect of $\gamma$-CD observed in nRT neurons at P9-10 and P17-24. However, the data for P9/10 L2/3 cortical neurons are consistent with data published previously
(Brown et al., 2015). Different regions of the nervous system reach maturation at different ages and it is possible that this may account for the regional variations observed. Interestingly, the endogenous neurosteroid tone that previously appeared to be lost during maturation re-emerges in the adult mouse cortex, which may have a significant physiological role.

\section{A comparison of synaptic GABAAR mIPSCs of cortical} layer 2/3 pyramidal neurons in adult WT, ob/ob and $d b / d b$ mice incorporating the use of cyclodextrin

As the behavioural studies were to be conducted in adult mice, it was decided to make recordings from adult layer $2 / 3$ cortex neurons for three reasons: 1) Viable recordings of nRT neurons of 
older animals are compromised by the high density of axonal projections (Cox et al., 1997; Pinault \& Deschenes, 1998). 2) Values for the mean $\tau_{\mathrm{W}}$ of $\mathrm{L} 2 / 3$ cortical GABA ${ }_{A} \mathrm{R}$ mIPSCs are relatively homogenous, in contrast to the mean $\tau_{\mathrm{W}}$ values of GABA $\mathrm{R}$ mIPSCs of LII neurons which are heterogenous (Mitchell et al., 2007), which makes inter-group comparison more difficult. 3) Layer $2 / 3$ pyramidal neurons of the somatosensory cortex are part of the pain pathway.

The developmental age of P60-75 was chosen because it facilitated a comparison with the $o b / o b$ mouse model of type-2 diabetes mellitus (T2DM). The $o b / o b$ mouse develops super-morbid obesity and exhibits a neuropathic phenotype and consequently develops hypersensitivity to pain by the age of P60-75 (Drel et al., 2006; Latham et al., 2009). To date, there are no published reports of the electrophysiological characterisation of $\mathrm{GABA}_{\mathrm{A}} \mathrm{R}$ function for the $o b / o b$ mouse.
Mice were weighed in order to confirm the presence of obesity. The $o b / o b$ and $d b / d b$ mice (P60-75) both had significantly greater body weights than the respective WT animals of the same age (Table S3, $P<0.05$ ). These data are consistent with the literature (Bates et al., 2005; Latham et al., 2009).

To exclude the presence of a direct effect of leptin itself recordings were additionally made in the $d b / d b$, which is able to synthesise leptin but lacks the receptor. There was a modest but significant reduction in the mIPSC decay $\left(\tau_{\mathrm{w}}\right)$ of cortical neurons between the diabetic mice and the corresponding WT littermates, but no significant difference in the $\tau_{\mathrm{w}}$, between the three WT strains $(P<0.05$; Table S4, Figure 3A,C).

Recordings were made to determine that neither the strain, nor the lack of leptin (directly) was an important factor in the shortening of mIPSC $\tau_{\mathrm{w}}$ with $\gamma$-CD. In the presence of intracellular $\gamma$-CD, there
A
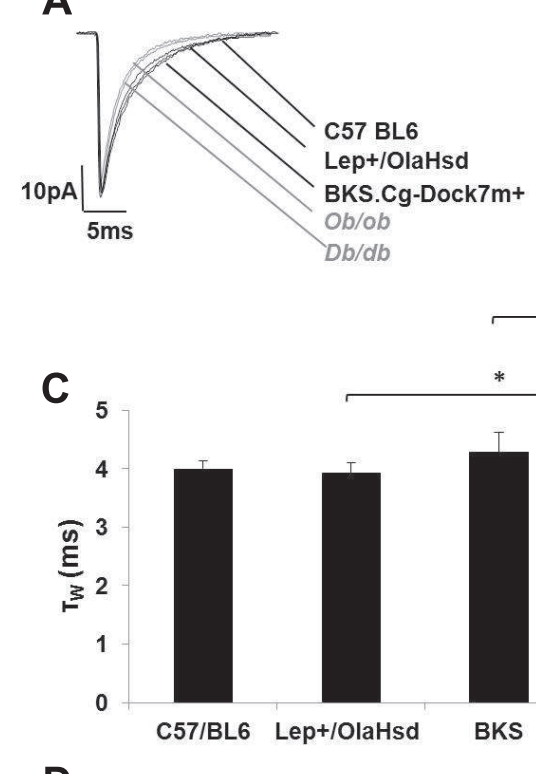

D

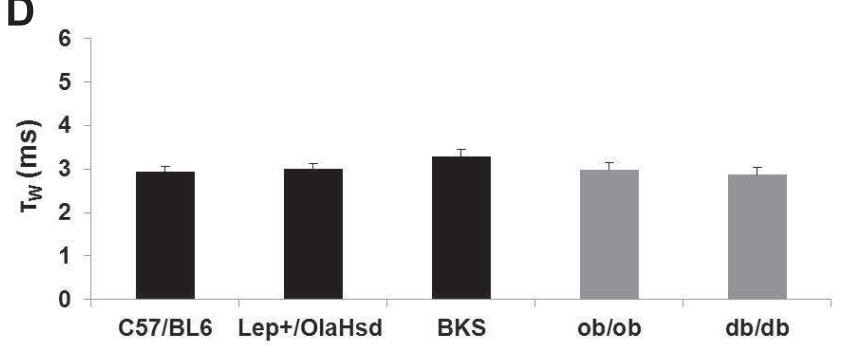

B
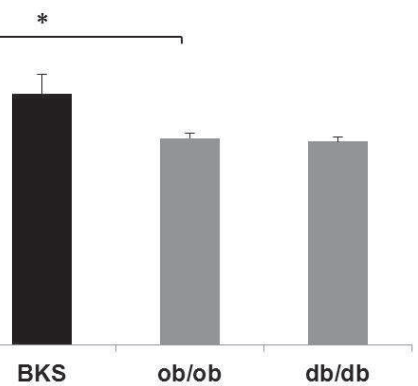

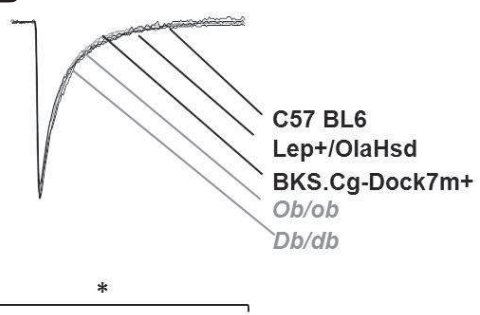

Figure 3. Mature cortical neurons of ob/ob $\& d b / d b$ mice exhibit shorter GABA $R$ mIPSCs compared to those from three different WT strains. Intracellular $\gamma$-CD reduces the duration of GABA $R$ mIPSCs of mature cortical neurons from different types of mice to a similar baseline level. (A) Superimposed exemplar GABA $A_{A}$ s mIPSCs from three WT strains (black) and two diabetic phenotypes (grey). (B) Superimposed exemplar GABA $A_{A}$-mediated mIPSCs from three WT strains (black) and two diabetic phenotypes (grey) with $0.5 \mu \mathrm{M} \gamma$-CD administered intracellularly. (C) Histogram illustrating the shorter cortical GABA $\mathrm{R}$ mIPSC $\tau_{w}$ of the diabetic mice and their corresponding WT strains $\left(n=8-25\right.$; Student's unpaired t test $\left.{ }^{*} P<0.05\right)$. (D) Histogram illustrating that there was no significant difference between all five strains of mice in the presence of intracellular $(\gamma-C D n=5-15$; One-way ANOVA $P>0.05)$. 
was no significant difference in the mIPSC $\tau_{\mathrm{w}}$ of between all five types of mice (Table S5, Figure 3D, $P>0.05$ ). These findings suggest that synaptic $\mathrm{GABA}_{\mathrm{A}} \mathrm{R}$ function is very similar across all these strains of mice included in the study when the endogenous neurosteroid tone is removed by $\gamma-\mathrm{CD}$. The results are also consistent with the hypothesis that there is a neurosteroid tone at P60-75, but that it is reduced in both mouse models of diabetic neuropathy. However, the data do not exclude the possibility that the sensitivity of $L 2 / 3$ cortical GABA ${ }_{A}$ Rs to neurosteroids may be reduced.

\section{A comparison of the effect of neurosteroids on cortical} layer 2/3 neurons in adult WT, ob/ob and $d b / d b$ mice

The lipophilic intravenous anaesthetics etomidate and propofol, which in common with neuroactive steroids enhance the function of $\mathrm{GABA}_{\mathrm{A}} \mathrm{Rs}$, require relatively prolonged incubation times to approach equilibrium in a brain slice preparation- over 1-2 hours (Benkwitz et al., 2007; Gredell et al., 2004). It is conceivable that the same is true for neurosteroids (Li et al., 2007) therefore recordings were made after incubation treatment with allopregnanolone and ganaxolone. In contrast to the relatively modest prolongation of mIPSCs described above with an acute steroid application protocol $\left(\tau_{\mathrm{w}}\right.$ : control $=4.0 \pm 0.3 \mathrm{~ms}, \mathrm{n}=7$; allopregnanolone $1 \mu \mathrm{M}=4.5 \pm 0.4 \mathrm{~ms}, \mathrm{n}=7$; paired Student's t test, $\mathrm{P}<0.05$ ), a 2-hour incubation of the brain slice preparation with nanomolar concentrations of allopregnanolone $(100-300 \mathrm{nM})$ produced a dramatic concentration-dependent increase of the WT GABA $\mathrm{A}$ mIPSCs (Table S6, Figure 4A,C,D; $P<0.05$ ). These results indicate that allopregnanolone is a potent modulator of synaptic $\mathrm{GABA}_{\mathrm{A}} \mathrm{Rs}$ in mature cortical neurons, but additionally demonstrate that the steroid effect is greatly underestimated when applied acutely. The large difference between acute bath application and the 2-hour incubation (see Additional material) is probably a consequence of the time required for the steroid to approach equilibrium within the brain slice. No such effect is observed in time-matched controls.

A 2-hour incubation of the $o b / o b$ brain slice preparation with allopregnanolone produced a clear concentration-dependent prolongation of $\mathrm{GABA}_{\mathrm{A}} \mathrm{R}$ mIPSC $\tau_{\mathrm{w}}$ (Table S6, Figure 4B-D; $P<0.05$ ). The effect of allopregnanolone was similar for WT, ob/ob and $d b / d b$ mice (Table S6; $P>0.05$ ). When the data were normalised to reflect the control mIPSC $\tau_{\mathrm{w}}$, there was no significant difference in the effect of between the three types of mice (Figure S1, $P>0.05$ ). These results suggest that the sensitivity of cortical $\mathrm{GABA}_{\mathrm{A}} \mathrm{Rs}$ to allopregnanolone in diabetic mice is similar to age-matched WT.

A 2-hour incubation with ganaxolone produced a significant concentration-dependent increase of the WT mIPSC $\tau_{\mathrm{w}}$, although the magnitude of the effect was less than that induced by allopregnanolone (Table S7, Figure 4E,G,H; $P<0.05$ ). In the $o b / o b$ and $d b / d b$ brain slices incubated with ganaxolone the mIPSC $\tau_{\mathrm{w}}$ prolongation was comparatively greater than for equivalent WT neurons, but there was no significant difference between the $o b / o b$ and $d b / d b$ (Table S7; $P>0.05$ ). These observations contrast with that of allopregnanolone. These findings suggest that there is a difference in the effect of ganaxolone incubation treatment (but not allopregnanolone) in the $o b / o b$ and $d b / d b$ mice compared to the WT mice.

Can mature layer 2/3 cortical neurons from WT, ob/ob and $d b / d b$ mice synthesise neurosteroids?

Progesterone and its metabolite dihydroxy-progesterone (DHP) do not modulate $\mathrm{GABA}_{\mathrm{A}}$ Rs directly (Belelli \& Herd, 2003; Brown et al., 2015), but require the activity of the enzymes $5 \alpha-\mathrm{R}$ and $3 \alpha-H S D$ in order to synthesise allopregnanolone (Figure 1; Schumacher et al., 2012; Stoffel-Wagner, 2003).

A 2-hour incubation with progesterone produced a relatively modest prolongation of mIPSC $\tau_{\mathrm{W}}$ in WT mice. The highest concentration of progesterone tested was only slightly more effective than the lowest concentration investigated here (Table S8, Figure 5A,C; $P<0.05)$. These results suggest that the enzymatic function $(5 \alpha-\mathrm{R}$ and $3 \alpha-H S D)$ is intact and neurosteroids may be synthesised with brain slice incubation of the precursor.

Progesterone incubation treatment also produced a similarly modest prolongation of mIPSC $\tau_{\mathrm{w}}$ in the $o b / o b$ and $d b / d b$ (Table S8, Figure 5B,C; $P<0.05)$. When the data for $\tau_{\mathrm{w}}$ were normalised. When the effects of $50 \mu \mathrm{M}$ progesterone were expressed as a percentage of the representative control, the steroid had a greater impact on the diabetic mice $(P<0.05)$, but there was no intergroup difference between the $o b / o b$ and $d b / d b$ mice $(P>0.05$; Table S8, Figure S1; Figure 5D).

Bath application of DHP $(3 \mu \mathrm{M})$ had no effect on the $\mathrm{GABA}_{\mathrm{A}} \mathrm{R}$ mIPSCs in WT neurons $\left(\tau_{\mathrm{w}}\right.$ : Control $=5 \pm 0.3 \mathrm{~ms}, \mathrm{n}=4 ; 3 \mu \mathrm{M}$ $\mathrm{DHP}=4.7 \pm 0.3 \mathrm{~ms}, \mathrm{n}=4, P>0.05)$. These findings are consistent with previous work on VB neurons (Brown et al., 2015). The lack of effect after the acute application of DHP contrasts to the modest effects of acutely applied allopregnanolone and ganaxolone (see Additional material). Contrastingly, 2 hours of incubation with DHP $(1-3 \mu \mathrm{M})$ produced a significant, concentration-dependent prolongation of $\mathrm{GABA}_{\mathrm{A}} \mathrm{R}$ mIPSCs in WT $(\mathrm{P}<0.05$; Table $\mathrm{S} 9$, Figure $5 \mathrm{E}, \mathrm{G})$. These results indicate that mature WT L2/3 cortical neurons have intact $3 \alpha-\mathrm{HSD}$ enzymatic function and are able to convert DHP into the active metabolite allopregnanolone. $3 \mu \mathrm{M}$ DHP incubation produced a more pronounced effect in the $o b / o b$ and $d b / d b$ mice compared to the WT $(P<0.05$, Table S9), indicating that not only is $3 \alpha$-HSD enzymatic function preserved in mature mice with T2DM, but may be up-regulated.

Selective inhibition of enzymes within the neurosteroid synthesis pathway in mature layer $2 / 3$ cortical neurons from WT, ob/ob and $d b / d b$ mice

Finasteride itself has no direct effect on GABA ${ }_{A}$ R mIPSCs, but pre-treatment with this $5 \alpha-\mathrm{R}$ enzyme inhibitor prevents the conversion of progesterone into $\mathrm{GABA}_{\mathrm{A}} \mathrm{R}$-active neurosteroid (Sanna et al., 2004). Recordings were made after at least 2 hours of incubation with finasteride and progesterone. Finasteride alone had no effect on WT mIPSC $\tau_{\mathrm{w}}$ but it did prevent the effect of progesterone (Table S10; $P<0.05$ ). Finasteride alone also had no 
A

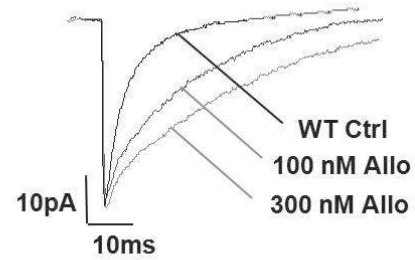

C

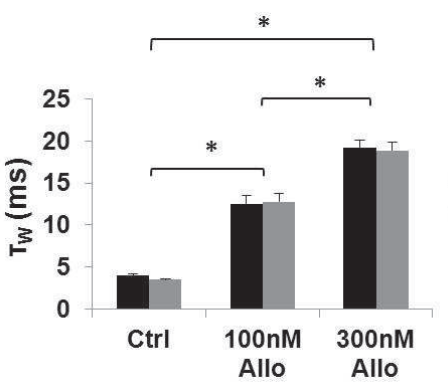

E

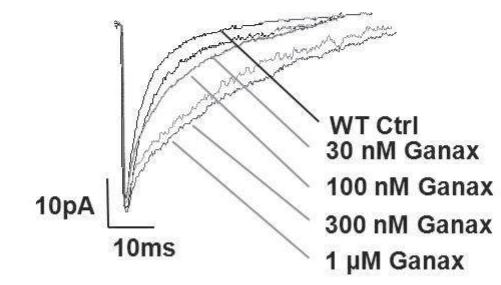

G

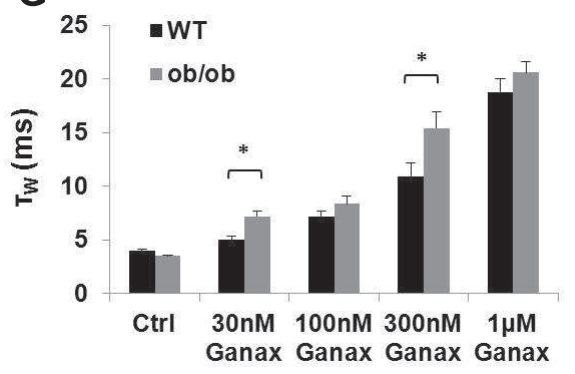

B

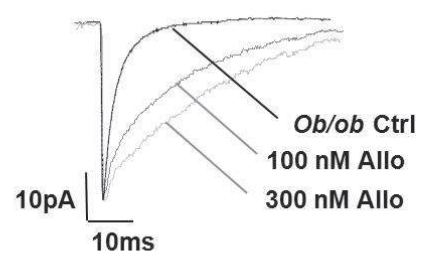

D

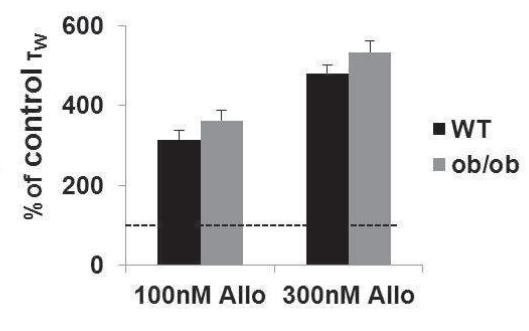

F

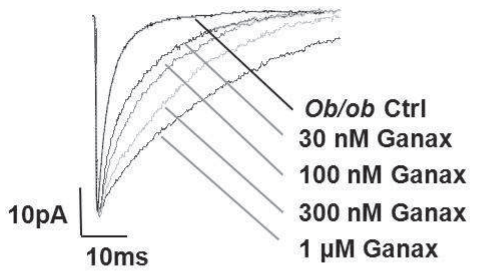

H

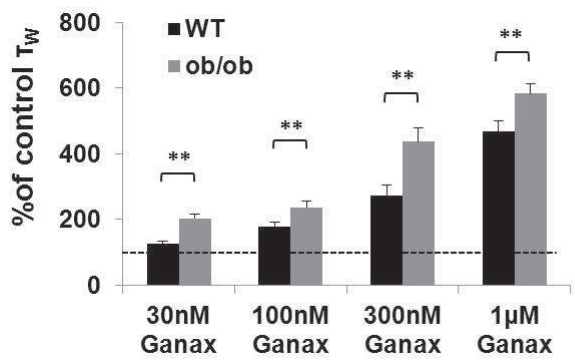

Figure 4. Prolonged exposure ( $2 \mathrm{hrs})$ of WT \& ob/ob mature cortical neurons to allopregnanolone (100-300 nM) greatly enhances the function of synaptic GABA Rs by a similar margin while ganaxolone has an exaggerated effect in ob/ob mice. (A \& B) Superimposed exemplar GABA $\mathrm{R}$ mIPSCs from representative control cortical neurons from mature WT and ob/ob mice respectively and from equivalent neurons after 2 hour brain slice incubation with $100 \mathrm{nM}$ and $300 \mathrm{nM}$ allopregnanolone. (C) Histogram illustrating the concentration-dependent effect of allopregnanolone on the cortical GABA $\mathrm{R}$ mIPSCs of ob/ob mice ( $n=6-25$; One-way ANOVA $P<0.05$. Post hoc Newman Keuls test revealed significant differences between control and both concentrations of allopregnanolone, which increased $\tau_{w}$ to $362 \pm 27 \%$ and $534 \pm 28 \%$ of control respectively $\left.{ }^{*} P<0.05\right)$. Note that there is no significant difference in response between the two types of mice $(n=8-9$; One-way RM ANOVA $P>0.05$ ). (D) Histogram comparing the concentration-dependent effects of allopregnanolone on the duration of GABA $A_{A}$ Rs mIPSC $\tau_{w}$ expressed as a percentage of control for WT (black) and ob/ob (grey) mice. The histogram illustrates that there is no significant difference in the effect of $300 \mathrm{nM}$ allopregnanolone on the cortical GABA $\mathrm{As}_{\mathrm{A}} \mathrm{mIPSCs}$ of WT and ob/ob neurons $(\mathrm{n}=8-9$; One-way RM ANOVA $P>0.05$ ). (E \& F) Superimposed exemplar $G_{A B A} R$ mIPSCs from representative control cortical neurons from mature WT and ob/ob mice respectively and from equivalent neurons after $\sim 2$ hour brain slice incubation with $30 \mathrm{nM}-1 \mu \mathrm{M}$ ganaxolone. (G) Histogram illustrating the concentration-dependent effect of ganaxolone $30 \mathrm{nM}-1 \mu \mathrm{M}$ on the GABA Rs mIPSCs of ob/ob mice (grey bars; One-way ANOVA $P<0.05$ ). Note the exaggerated effect of ganaxolone incubation treatment on the cortical GABA ${ }_{A} R s$ mIPSCs of ob/ob mice (grey bars) in comparison to WT mice (black bars) for $30 \mathrm{nM}$ and $300 \mathrm{nM}$ ganaxolone (One-way RM ANOVA, ${ }^{*} P<0.05$ respectively). (H) Histogram comparing the concentration-dependent effects of ganaxolone on the duration of GABA $A_{A}$ mIPSC $\tau_{w}$ expressed as a percentage of control for WT (black) and ob/ob (grey) mice. The histogram illustrates that ganaxolone has an exaggerated effect in ob/ob mice One-way RM ANOVA $\left.{ }^{*} P<0.05\right)$. Ctrl = control; Allo = allopregnanolone; Ganax = ganaxolone. 
A

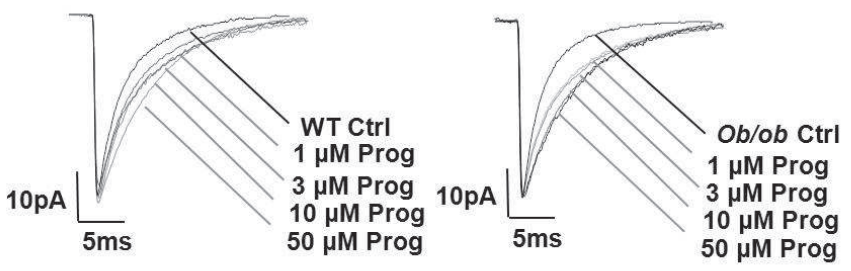

C

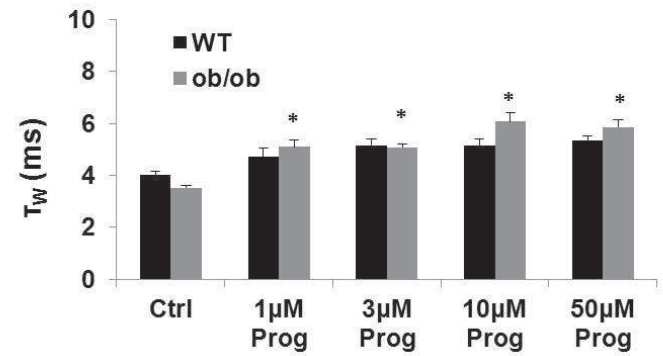

D

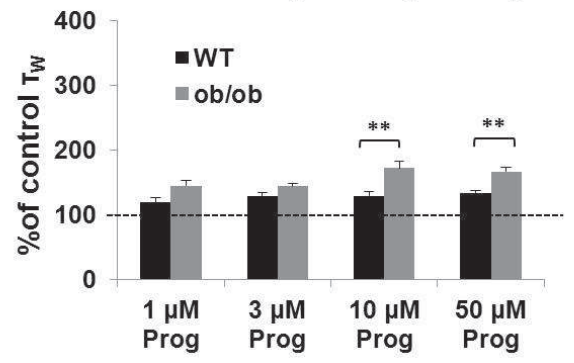

$\mathbf{E}$

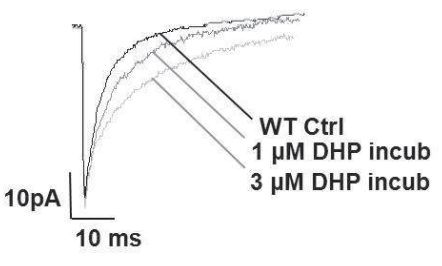

$\mathbf{F}$

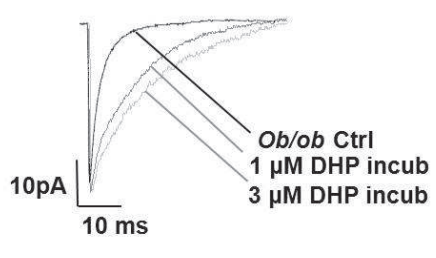

G

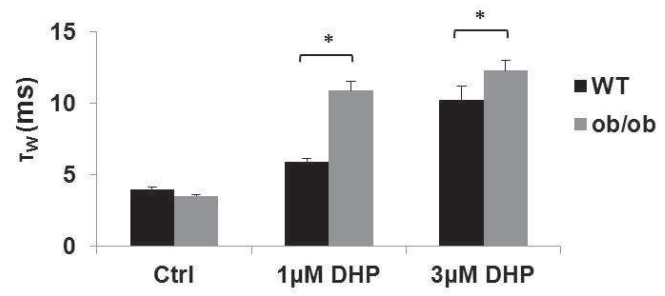

H

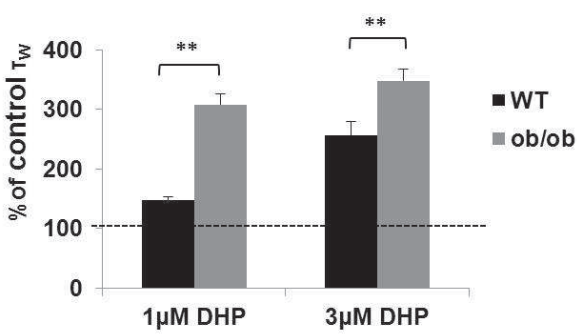

Figure 5. Prolonged exposure $(\sim 2 \mathrm{hrs})$ of mature cortical neurons to progesterone $(1-50 \mu \mathrm{M})$ and $\mathrm{DHP}(1-3 \mu \mathrm{M})$ enhances the function of synaptic GABA ${ }_{A}$ Rs, suggesting that both WT \& ob/ob neurons can synthesise allopregnanolone. (A \& B) Superimposed exemplar $\mathrm{GABA}_{A} \mathrm{R}$ mIPSCs from a representative control mature WT and ob/ob cortical neurons and from equivalent neurons after 2 hour brain slice incubation with $1 \mu \mathrm{M}-50 \mu \mathrm{M}$ progesterone. (C) Histogram illustrating the significant but modest effect of progesterone incubation treatment on WT and ob/ob cortical GABA Rs mIPSCs (grey) that was not concentration-dependent (One-way ANOVA * $P<0.05$ ). (D) Histogram illustrating the concentration-independent effect of progesterone on the duration of GABA $R s$ mIPSC $\tau_{w}$ expressed as a percentage of control. Note that when the effect of progesterone $50 \mu \mathrm{M}$ was expressed as a percentage of the representative control, the steroid had a greater impact on the ob/ob mice $\left(n=7-12\right.$, One-way RM ANOVA $\left.{ }^{* *} P<0.05\right)$. (E \& F) Superimposed exemplar GABA R mIPSCs from a representative control mature WT and ob/ob cortical neurons and from equivalent neurons after 2 hour brain slice incubation with $1-3 \mu \mathrm{M}$ DHP. (G) Histogram illustrating the significant concentration-dependent effect of DHP on the duration of WT and ob/ob cortical GABA Rs mIPSCs ( $n=10-25$; One-way ANOVA $P<0.05)$. Note the exaggerated response of the ob/ob vs. the WT cortical neurons for $1-3 \mu M$ DHP $(n=9-10$, one-way ANOVA ${ }^{*} P<0.05$ ). (H) Histogram illustrating that $1-3 \mu \mathrm{M}$ DHP has an exaggerated effect in ob/ob (grey) vs. WT (black) mice when the effect is expressed as a percentage of the respective control value (One-way RM ANOVA $\left.{ }^{* \star} P<0.05\right)$. Ctrl = control; DHP $=$ dihydroxyprogesterone; Prog $=$ progesterone

effect on $o b / o b$ mIPSC $\tau_{\mathrm{w}}$ of mice, but it did prevent the effect of progesterone (Table S10; $P<0.05$ ) indicating that progesterone requires the $5 \alpha-\mathrm{R}$ for it to be converted to its' active metabolites, (although do not prove neurosteroid synthesis by the neurons itself). Finasteride alone had no effect on mIPSC $\tau_{\mathrm{w}}$, despite the suggested presence of a modest endogenous neurosteroid tone in mature WT mice. This apparent paradox may be explained by comparing how finasteride and $\gamma$-CD act. $\gamma$-CD will remove the endogenous neurosteroid present, whereas although finasteride should prevent new allopregnanolone synthesis, it will have little impact on that already present. Therefore, the apparent lack of an effect of finasteride may reflect the relatively slow turnover of pre-synthesised allopregnanolone and is consistent with the literature (Brown et al., 2015).

The $3 \alpha-H S D$ enzyme inhibitor provera suppresses the effects of DHP, but not ganaxolone on $\mathrm{GABA}_{\mathrm{A}} \mathrm{R}$-mediated mIPSCs of mature cortical neurons

Recordings were made in WT mice after at least 2 hours of incubation with provera and DHP, or provera and ganaxolone. Provera alone exerted a modest effect on mIPSC $\tau_{\mathrm{w}}$ but, in addition, it prevented the effect of DHP (Table S11, Figure S2 A,B; $P<0.05$ ). 
Provera did not inhibit the effect of ganaxolone on $\tau_{\mathrm{w}}$ in WT mice (Table S11, Figure S2 C,D, $P>0.05$ ). These results confirm that DHP requires enzymatic conversion by $3 \alpha$-HSD for it to induce a prolongation of $\tau_{\mathrm{w}}$. In contrast, ganaxolone was unaffected by $3 \alpha$-HSD inhibition with provera.

The $3 \alpha-H S D$ enzyme inhibitor indometacin suppresses the effects of DHP and ganaxolone, but not those of allopregnanolone on $\mathrm{GABA}_{\mathrm{A}} \mathrm{R}$-mediated mIPSCs of mature cortical neurons

Indometacin alone had no effect on $\tau_{\mathrm{w}}$, but it also prevented the effect of DHP (Table S12, Figure S2 E,F; $P<0.05$ ). By contrast, indometacin had no effect on the prolongation of mIPSC $\tau_{\mathrm{w}}$ by preincubated allopregnanolone (Table S13, Figure S2 G,H; $P>0.05$ ) confirming that allopregnanolone does not require $3 \alpha-\mathrm{HSD}$ in order to modulate $\mathrm{GABA}_{\mathrm{A}} \mathrm{R}$ mIPSCs. Indometacin did not increase the effect of allopregnanolone by potentially inhibiting its metabolism to an inactive form. These experiments with another $3 \alpha-\mathrm{HSD}$ enzyme inhibitor confirm that DHP requires conversion to a more active form by $3 \alpha$-HSD in order for it to induce prolongation of $\mathrm{GABA}_{\mathrm{A}} \mathrm{R}$ mIPSC decay time. By contrast, indometacin exhibited concentration-dependent inhibition of ganaxolone incubation treatment on $\tau_{\mathrm{w}}$ (Table S13, Figure S2 I,J, $P<0.05$ ). These results with ganaxolone were unexpected given the lack of impact that indometacin had on the effectiveness of allopregnanolone. Indeed, inhibiting $3 \alpha-H S D$ with provera had no impact on ganaxolone, but prevented the effect of DHP on GABA $\mathrm{R}$ mIPSC $\tau_{\mathrm{w}}$. This raises the question as to whether ganaxolone is an allosteric modulator of the $\mathrm{GABA}_{A} \mathrm{R}$ and a precursor to a more active neurosteroid such as allopregnanolone. Alternatively, it raises the question of whether indometacin could be a silent competitive steroid antagonist at the $\mathrm{GABA}_{\mathrm{A}} \mathrm{R}$ and prevent the action of ganaxolone by that mechanism (explored in next section).

The effect of pipette-applied neurosteroids on layer $2 / 3$ cortical GABA $A_{A}$ m mIPSCs in mature WT mice (P60-75)

Acute allopregnanolone had only a modest effect on the $\mathrm{GABA}_{\mathrm{A}} \mathrm{R}-$ mediated mIPSCs decay time (see Additional material), but was far more efficacious in this respect when brain tissue slices were incubated with steroid for $>2$ hours, suggesting that the steroid is relatively slow to equilibrate within the tissue. It has been proposed that endogenous neurosteroids may be synthesised in the postsynaptic neuron and act in an autocrine manner to influence GABA-ergic transmission (Agis-Balboa et al., 2006; Lambert et al., 2009). It is implicit in this model that intracellular steroid would modulate the GABA $\mathrm{Rs}_{\mathrm{A}}$ of the postsynaptic neuron and the recording pipette can be employed to deliver drugs to the neuron interior (Evans \& Marty, 1986). Recordings were made with allopregnanolone, or ganaxolone present in the recording pipette to explore whether the steroid could modulate synaptic GABA Rs when delivered to the intracellular compartment. These recordings were compared to separate control recordings (i.e. they were not paired). The presence of allopregnanolone in the recording pipette significantly increased the WT mIPSC $\tau_{\mathrm{w}}$ in a concentration-dependent manner (Table S14, Figure S3 A,C; $P<0.05$ ). Here, the higher concentration of allopregnanolone $(10 \mu \mathrm{M})$ had a comparatively large concentration-dependent effect on $\mathrm{GABA}_{\mathrm{A}} \mathrm{R}$ mIPSCs when presented acutely within the recording electrode. This finding indicates that neurosteroids are able to exert their effect via the intracellular compartment and is in agreement with the literature (Akk et al., 2005).

The concentrations of pipette-applied allopregnanolone are relatively high, but the time scale from application to recording is short ( $<10$ minutes) and dialysis rate of the intracellular contents may be an influential limiting factor. The presence of ganaxolone in the recording pipette also significantly increased the WT mIPSC $\tau_{\mathrm{w}}$ in a concentration-dependent manner (Table S15, Figure S3 E, G, $P<0.05$ ). The effect of pipette-applied ganaxolone is consistent with the recordings described above with allopregnanolone, although ganaxolone had a less pronounced effect on $\mathrm{GABA}_{\mathrm{A}} \mathrm{R}$ mIPSCs. Collectively these experiments illustrate that steroid penetration of brain slice tissue is a significant limiting factor, the intracellular application is an effective method of presenting neuroactive steroids to GABA ${ }_{A}$ Rs (Table S14-Table S16, Figure 1, Figure S3 A-H) and that, in these neurons, allopregnanolone is a more effective modulator of the synaptic $\mathrm{GABA}_{\mathrm{A}} \mathrm{R}$ than ganaxolone (Figure S3 C,D, G,H).

Recordings were also made in $o b / o b$ neurons with allopregnanolone, or ganaxolone, present in the recording pipette. The $o b / o b$ mIPSC $\tau_{\mathrm{w}}$ was increased by the presence of allopregnanolone in the recording pipette (Table S14, Figure S3 B,C; $P<0.05$ ). After normalisation, intracellular allopregnanolone $3-10 \mu \mathrm{M}$ increased $\tau_{\mathrm{w}}$ to similar percentages of the strain representative controls (Table S14, Figure S3 D, $P>0.05$ ). These findings are consistent with the hypothesis that there is no difference in the sensitivity of the cortical $\mathrm{GABA}_{\mathrm{A}} \mathrm{R}$ to neurosteroids between the $o b / o b$ and WT mice.

The $o b / o b$ mIPSC $\tau_{\mathrm{w}}$ was increased by the presence of ganaxolone in the recording pipette (Table S15, Figure S3 F,G, $P<0.05$ ). Ganaxolone did not have a concentration-dependent effect on $o b / o b$ cortical GABA $\mathrm{R}$ mIPSCs when acutely delivered intracellularly and the magnitude of the effect was less than that produced by equivalent pipette concentrations of allopregnanolone (Table S14-Table S15, Figure S3 C,D, G,H,L, $P>0.05$ ). There was no difference in the GABA $\mathrm{R}$ mIPSC $\tau_{\mathrm{W}}$ between the $o b / o b$ and the WT when treated with intracellular ganaxolone. This finding is consistent with the recordings described above with allopregnanolone, although intracellular ganaxolone had a less pronounced effect.

In order to explore whether indometacin could be a silent competitive antagonist at the $\mathrm{GABA}_{\mathrm{A}} \mathrm{R}$ (and therefore prevent modulation by ganaxolone) recordings were made with indometacin \pm ganaxolone presented in the pipette. The WT mIPSC $\tau_{\mathrm{w}}$ was unchanged by the presence of indometacin in the pipette and indometacin had no effect on the modulatory action of ganaxolone (Table S16, Figure S3 I,J, $P>0.05$ ).

Recordings were also made in $o b / o b$ neurons with indometacin \pm ganaxolone presented in the pipette. The mIPSC $\tau_{\mathrm{w}}$ in $o b / o b$ mice was unaffected by the presence of indometacin in the pipette and indometacin had no effect on the modulatory action of ganaxolone 
(Table $\mathrm{S} 16, P>0.05$ ). It is possible that indometacin may inhibit the action of ganaxolone by preventing its conversion to a more active compound (such as allopregnanolone).

The WT and $o b / o b$ mIPSC $\tau_{\mathrm{w}}$ was unaffected by the presence of DHP in the recording pipette (Table S17, $P>0.05$ ). These findings contrast with the significant effects of intracellular allopregnanolone and ganaxolone and are consistent with the idea that DHP is a precursor compound (Figure 1, Figure S3 K,L). Considering these results it would be difficult to make the case for the alternative hypothesis that $\mathrm{GABA}_{A} \mathrm{R}$ sensitivity is increased in $o b / o b$ and $d b / d b$ mice.

\section{Behavioural work}

The developmental age of P60-75 was chosen for both electrophysiological and behavioural experiments as it represents physiological maturity and facilitates a comparison with the $o b / o b$ mouse model of T2DM, which develops hypersensitivity to pain by this age (Drel et al., 2006; Latham et al., 2009).

\section{ob/ob mice have impaired sensorimotor coordination in comparison to WT mice}

The $o b / o b$ mice were able to remain on the rotarod for a significantly shorter time than were WT mice (WT $=216 \pm 14 \mathrm{~s}, \mathrm{n}=15$; $o b / o b=21 \pm 5 \mathrm{~s}, \mathrm{n}=15$; Mann-Whitney Rank Sum test, $P<0.001$; Figure 6A). The impaired rotarod performance of the $o b / o b$ mouse is consistent with a previous report (Mayers et al., 2009). It is not possible to have obese WT mice as controls because those obese mice would be likely to have similar neurological consequences as the $o b / o b$ mice.

\section{ob/ob mice exhibit prolonged tail withdrawal from noxious} heat in comparison to WT mice

The tail flick test was used to characterise the response of the WT and the $o b / o b$ mouse to three distinct temperatures. At $48^{\circ} \mathrm{C}$ and $50^{\circ} \mathrm{C} o b / o b$ mice exhibited significantly longer tail withdrawal latencies compared to WT mice (Table S18, Figure 6B, $P<0.05$ ). By contrast, there was no significant difference with a water temperature of $46^{\circ} \mathrm{C}$ (Table S18, Figure $6 \mathrm{~B}, P>0.05$ ). These findings are consistent with the phenomenon of thermal hypoalgesia in $o b / o b$ mice reported by Drel et al. (2006), but conflict with the thermal hyperalgesia reported by Latham et al. (2009).

\section{Ganaxolone increases tail withdrawal latency in WT mice.} Ganaxolone impairs thermal nociception in WT mice

The tail flick test is a useful tool for assessing thermal nociception. Ganaxolone was considered a priori considered to be a metabolically stable synthetic analogue of allopregnanolone, the molecular structure of which differs only by having an extra methyl group that prevents oxidation to an inactive form and has previously been used in clinical trials (Carter et al., 1997). Ganaxolone required to be solubilised with hydroxypropyl $\beta$-CD prior to intraperitoneal injection (Besheer et al., 2010; Carter et al., 1997; Reddy \& Rogawski, 2010). There were no significant differences in the baseline withdrawal latencies in response to a noxious thermal stimulus $\left(50^{\circ} \mathrm{C}\right)$ between the four groups of mice used to examine the effects of ganaxolone (Table S19, Figure 6C, $P>0.05$ ). Ganaxolone induced a dose-dependent prolongation of tail withdrawal latency in WT mice after 30 minutes and this effect lasted more than 90 minutes (Table S19, Figure $6 \mathrm{C}, P<0.05$ ). These data suggest that ganaxolone exhibits a dose-dependent analgesic effect in a test of thermal nociception in WT mice. This finding is consistent with the intrathecal administration of ganaxolone (Asiedu et al., 2012) and also other reports of the analgesic effects of similar neurosteroids in rats in the setting of post-chemotherapy neuropathy (Meyer et al., 2010; Meyer et al., 2011).

\section{High doses of ganaxolone impair rotarod performance of} WT mice

Only the highest dose of ganaxolone significantly impaired the performance of WT mice on the rotarod. There was no significant difference in the baseline rotarod performance of the four groups in the study (Table S20, Figure 6D, $P>0.05$ ). However, at 15 , 30 and 60 minutes post-injection the highest dose of ganaxolone $(30 \mathrm{mg} / \mathrm{kg}$ ) significantly impaired performance of WT mice on the rotarod (Table S20, Figure 6D, $P<0.05$ ). The effect of ganaxolone $(30 \mathrm{mg} / \mathrm{kg})$ was no longer apparent at 120 minutes post-injection (Table S20, Figure 6D, $P>0.05$ ). Taken in conjunction with the tail flick data, these data suggest that ganaxolone exhibits an analgesic effect at a dose of $10 \mathrm{mg} / \mathrm{kg}$ but only impairs rotarod performance in WT mice at higher doses such as $30 \mathrm{mg} / \mathrm{kg}$. In addition, the dose-dependent effect on rotarod performance is consistent with the literature (Carter et al., 1997).

\section{ob/ob mice exhibit mechanical hypersensitivity in comparison to WT mice}

von Frey $(\mathrm{vF})$ filaments have previously been employed via the up-down method to demonstrate that the $o b / o b$ mechanical hypersensitivity by the age of P60 (Drel et al., 2006; Latham et al., 2009). The $0.16 \mathrm{~g}, 0.4 \mathrm{~g}$ and $0.6 \mathrm{~g} \mathrm{vF}$ filaments elicit withdrawal responses on $25 \%, 40 \%$ and $60 \%$ of occasions respectively in WT mice. If the $o b / o b$ mouse has an exaggerated response to these filaments this would be consistent with mechanical hypersensitivity (Merskey \& Bogduk, 1994). The $1 \mathrm{~g} \mathrm{vF}$ filament elicited a withdrawal response on approximately $90 \%$ of occasions, therefore it is considered to be a clear test of mechanical nociceptive pain in the WT mouse. This method was adapted from work published in rats with neuropathic sensitisation (Meyer et al., 2011). The $o b / o b$ mice responded significantly more frequently than the WT mice to the $0.16 \mathrm{~g}, 0.4 \mathrm{~g}$ and $0.6 \mathrm{~g}$ filaments (Table S21, Figure 6E, $P<0.05)$. By contrast, there was no significant difference in the frequency of responses to the $1 \mathrm{~g}$ vF filament (Table S21, Figure 6E, $P>0.05)$. These results confirm the presence of mechanical hypersensitivity in the $o b / o b$ mouse, which is consistent with reports in the literature (Drel et al., 2006; Latham et al., 2009).

Ganaxolone reduces mechanical hypersensitivity in $o b / o b$ mice and reduces mechanical nociceptive pain in both WT and $o b / o b$ mice

$\mathrm{vF}$ filaments were used for the comparison of mechanical sensitivity of WT and $o b / o b$ mice before and after intraperitoneal drug administration. The $\beta$-CD vehicle had no impact on the response to any of the $\mathrm{vF}$ filaments in WT or ob/ob mice (Table S22, $P>0.05)$. Ganaxolone $(10 \mathrm{mg} / \mathrm{kg}$ ) had no impact on the response to the $0.16 \mathrm{~g}, 0.4 \mathrm{~g}$ or $0.6 \mathrm{~g} \mathrm{vF}$ filaments in the WT mouse (Table S23, Figure 6F, $P>0.05$ ) but ganaxolone did reduce the response of 

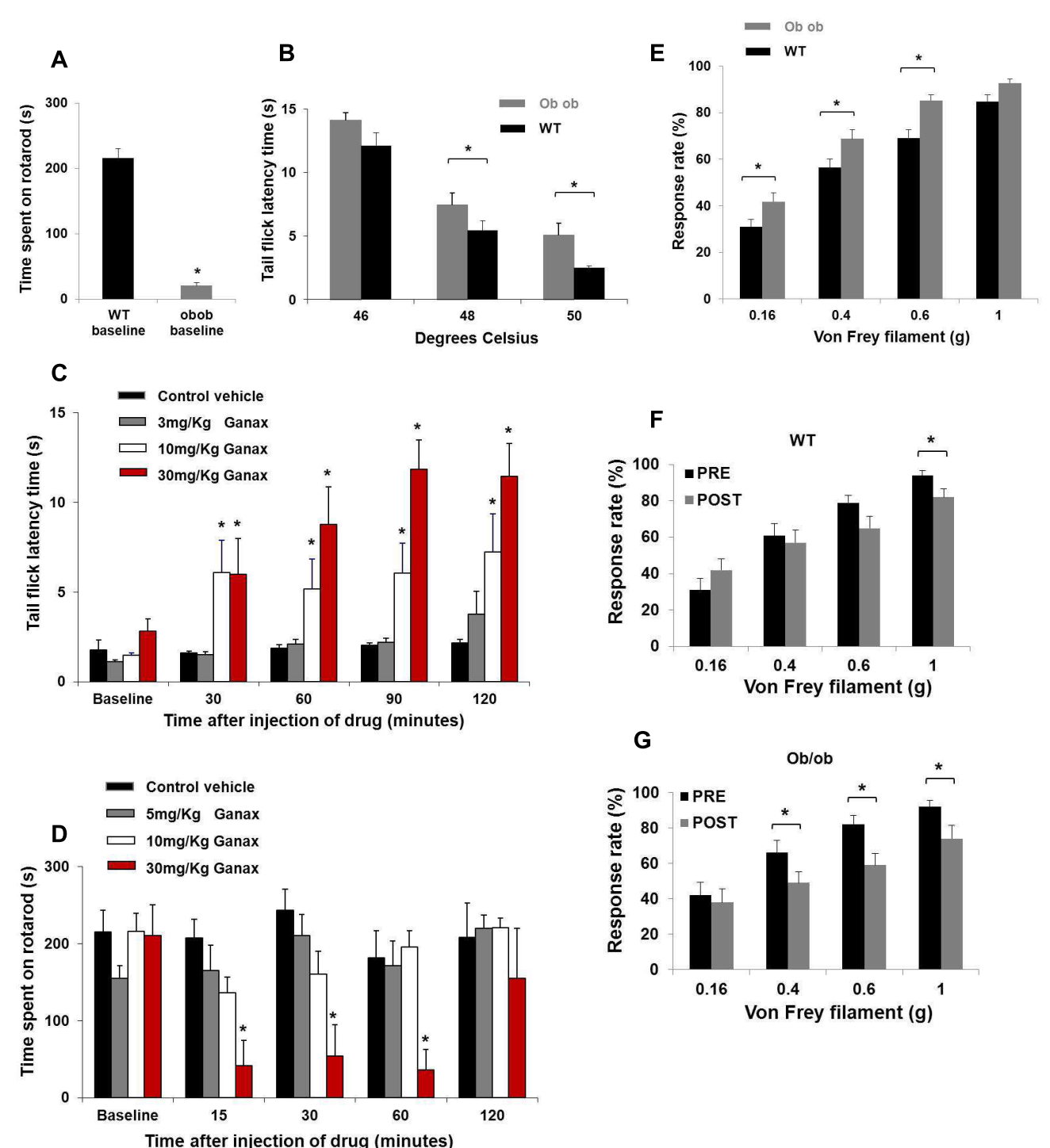

Figure 6. ob/ob mice have impaired sensorimotor coordination, exhibit hypoalgesia to noxious heat and mechanical hypersensitivity in comparison to WT mice. Ganaxolone impairs thermal nociception in WT mice at doses low enough to preserve rotarod performance. Ganaxolone reduces mechanical hypersensitivity in ob/ob mice and reduces mechanical nociceptive pain in both WT and ob/ob mice. (A) Histogram illustrating the dramatic impairment of sensorimotor function exhibited by mature ob/ob mice. The ob/ob mice were able to remain on the accelerating rotarod for a significantly shorter time than were WT mice $(n=15$; Mann-Whitney Rank Sum test $P<0.001)$. (B) Histogram illustrating that mature ob/ob mice have a delayed response to thermal noxious stimuli in comparison to age-matched WT mice. $(P<0.05)$. There was no significant difference at the less noxious temperature of $46^{\circ} \mathrm{C}(\mathrm{n}=20$ per group, Mann-Whitney Rank Sum test $P>0.05$ ). A maximum withdrawal latency of 15 seconds was enforced to minimise the possibility of tissue damage. (C) Histogram illustrating that $o b / o b$ mice exhibit mechanical hypersensitivity in comparison to WT mice. The ob/ob mice responded significantly more frequently than the WT mice to the $0.16 \mathrm{~g}, 0.4 \mathrm{~g}$ and $0.6 \mathrm{~g}$ filaments $(P<0.05)$. By contrast, there was no significant difference in the frequency of responses to the $1 \mathrm{~g} \mathrm{vF}$ filament (Mann-Whitney Rank Sum test $P>0.05$ ). These results confirm the presence of mechanical hypersensitivity in the ob/ob mouse. (D) Histogram illustrating that ganaxolone induced a dose-dependent prolongation of tail withdrawal latency in WT mice after 30 minutes $(P<0.05)$. The solubilising vehicle $\beta$-CD had no effect (Kruskall Wallis One-Way ANOVA on ranks $P>0.05)$. (E) Histogram showing that at 15,30 and 60 minutes post-injection the highest dose of ganaxolone $(30 \mathrm{mg} / \mathrm{kg})$ significantly impaired performance of WT mice on the rotarod $(P<0.05)$. The effect of ganaxolone $(30 \mathrm{mg} / \mathrm{kg})$ was no longer apparent at 120 minutes post-injection $(P>0.05)$. The solubilising vehicle $\beta-C D$ had no effect on rotarod performance (Kruskall Wallis One-Way ANOVA on ranks $P>0.05$ ). (F) Histogram illustrating that ganaxolone had no impact on the response to the $0.16 \mathrm{~g}, 0.4 \mathrm{~g}$ or $0.6 \mathrm{~g} \mathrm{vF}$ filaments in WT mice $(P>0.05)$ but ganaxolone did reduce the response of WT mice to the $1.0 \mathrm{~g} \mathrm{vF}$ filament ( $n=10$ per group, Wilcoxon signed rank test (before $\&$ after) $P<0.05)$. These data suggest that ganaxolone is analgesic for mechanical nociceptive pain in WT mice. WT mice do not exhibit hypersensitivity under normal conditions; therefore it is not unexpected that these drugs had no effect on the response to the smaller vF filaments. (G) Histogram illustrating that ganaxolone had no impact on the response to the $0.16 \mathrm{~g} \mathrm{vF}$ filament the ob/ob mouse $(P>0.05)$. In contrast, ganaxolone reduced the response of the $o b / 0 b$ mouse to the $0.4 \mathrm{~g}, 0.6 \mathrm{~g}$ and $1 \mathrm{~g} \mathrm{vF}$ filaments ( $\mathrm{n}=10$ per group, Wilcoxon signed rank test (before \& after) $P<0.05$ ). Ganaxolone reduced the response of the $\mathrm{ob} / \mathrm{ob}$ mouse to the $0.4 \mathrm{~g}$ and the $0.6 \mathrm{~g} \mathrm{vF}$ filaments, which is consistent with the idea that this neuroactive steroid may reduce mechanical hypersensitivity. As described earlier, the $1.0 \mathrm{~g} v \mathrm{~F}$ filament induces a withdrawal response on $\sim 85 \%$ of occasions in the WT and $~ 93 \%$ in the ob/ob mouse and may therefore be considered as an unambiguous test of mechanical nociceptive pain. Taken as a whole, these results show that ganaxolone was effective for mechanical nociceptive pain in both strains of mice. 
WT mice to the $1.0 \mathrm{~g}$ vF filament (Table S23, Figure 6F, $P<0.05$ ). These data suggest that ganaxolone is analgesic for mechanical nociceptive pain in WT mice. By definition, WT mice do not exhibit hypersensitivity or allodynia under normal conditions; therefore it is perhaps unsurprising that these drugs did not impact on the response to the smaller $\mathrm{vF}$ filaments.

Ganaxolone had no impact on the response rate to the $0.16 \mathrm{~g} \mathrm{vF}$ filament in $o b / o b$ mice (Table S24, Figure 6G, $P>0.05$ ), but in contrast, ganaxolone reduced the response rate of $o b / o b$ mice to the $0.4 \mathrm{~g}, 0.6 \mathrm{~g}$ and $1 \mathrm{~g} \mathrm{vF}$ filaments (Table S24, Figure 6G, $P<0.05)$. $o b / o b$ mice have exaggerated baseline response rates to the $0.16 \mathrm{~g}, 0.4 \mathrm{~g}$ and $0.6 \mathrm{~g} \mathrm{vF}$ filaments in comparison to WT mice (Figure 6E). Ganaxolone reduced the response rates of $o b / o b$ mice to the $0.4 \mathrm{~g}$ and $0.6 \mathrm{~g} \mathrm{vF}$ filaments, which is consistent with the idea that these neurosteroids may reduce mechanical hypersensitivity. As described earlier, the $1.0 \mathrm{~g} \mathrm{vF}$ filament induces a withdrawal response on $\sim 85 \%$ of occasions in WT mice and $\sim 93 \%$ in $o b / o b$ mice (Figure $6 \mathrm{E}$ ) and may therefore be considered as an unambiguous test of mechanical nociceptive pain. Taken as a whole, these results show that ganaxolone was effective for mechanical nociceptive pain in both strains of mice.

\section{Discussion}

The decay time of $\mathrm{GABA}_{\mathrm{A}} \mathrm{R}$ mIPSCs decreases with development at three levels of the pain pathway. $\mathrm{GABA}_{\mathrm{A}} \mathrm{Rs}$ from pain pathway neurons are sensitive to modulation by neurosteroids, and this was explored using $\gamma-\mathrm{CD}$ applied within the recording pipette suggesting that neurosteroids may be synthesised within neurons themselves. The endogenous neurosteroid tone that previously appeared to be lost with maturation re-emerges in the adult mouse cortex, which is suggestive of a significant physiological role. Layer $2 / 3$ pyramidal neurons of the somatosensory cortex are involved in the pain pathway, exhibit relatively homogenous $\mathrm{GABA}_{A} \mathrm{R}$ mIPSCs and are accessible for electrophysiological experimentation in mature animals. In contrast, there are inherent difficulties in studying neurons from other parts of the pain pathway in mature mice. Specifically, there is a relatively wide variation in decay time of $\mathrm{GABA}_{\mathrm{A}} \mathrm{R}$ mIPSCs from Lamina II neurons of the spinal cord (Mitchell et al., 2007) making it very challenging to assess the effects of pharmacological agents on decay time. Separately, thalamic neurons of mice over the age of P25 have a high density of axonal projections that obscures visualisation of individual neurons (Cox et al., 1997; Pinault \& Deschenes, 1998).

There are no published reports of the electrophysiological characterisation of synaptic $\mathrm{GABA}_{\mathrm{A}} \mathrm{R}$ function for T2DM. It was unknown whether neurosteroid tone would be altered in mice with diabetic neuropathy. In inflammatory pain, neurosteroidogenesis is upregulated to mediate a form of endogenous analgesia by enhancing GABAergic neural inhibition (Poisbeau et al., 2005). The $o b / o b$ model of T2DM is particularly useful for the study of neuropathic pain because it develops a more clinically relevant form of diabetes than other models (Cefalu, 2006; Drel et al., 2006; Latham et al., 2009; Lindstrom, 2007; Sullivan et al., 2007). However, it should be noted that no animal model of diabetes fully replicates the human phenotype. $o b / o b$ mice are deficient of the hormone leptin and it was considered that leptin itself may modulate $G_{A B A} R$ function (Solovyova et al., 2009). Therefore, recordings were made in a second mouse model of T2DM, the $d b / d b$ mouse, which is able to synthesise leptin but lacks the leptin receptor (Bates et al., 2005; Cefalu, 2006).

GABA $_{\mathrm{A}} \mathrm{R}$ mIPSCs from both $o b / o b$ and $d b / d b$ mice had significantly shorter decay times than the three WT strains, making it unlikely that leptin is involved. A decrease in the sensitivity of the $\mathrm{GABA}_{\mathrm{A}} \mathrm{R}$ to allosteric modulators such as neurosteroids would be a possible explanation for the shorter GABA $\mathrm{R}$ mIPSCs. However, reduced $\mathrm{GABA}_{A} \mathrm{R}$ sensitivity is inconsistent with the exaggerated effect of ganaxolone and DHP in $o b / o b$ and the similar effect of allopregnanolone in both WT and diabetic cortical neurons. Pipette-applied allopregnanolone or ganaxolone induced the same concentration-dependent increase in mIPSC decay time, in $o b / o b$ and WT, in keeping with Akk et al. (2005). A possible explanation may be that in T2DM mice there is a reduction in the endogenous neurosteroid tone, which is caused by a common pathological insult. Reduced neurosteroid tone could result in diminished GABAergic inhibition and subsequently a hypersensitive phenotype. Theoretically, other endogenous compounds that modulate the $\mathrm{GABA}_{\mathrm{A}} \mathrm{R}$ such as endocannabinoids may be affected by a common mechanism in T2DM; however the selective effects of the neurosteroid scavenger $\gamma-\mathrm{CD}$ (in comparison to the lack of effect with $\alpha-C D$ and $\beta$-CD) make this less likely. $\gamma-C D$ reduced the $\mathrm{GABA}_{\mathrm{A}} \mathrm{R}$ mIPSC decay time to similar baseline values for all five lines of mice. These findings are consistent with the hypothesis that mature WT mice possess an endogenous autocrine neurosteroid tone that may fine-tune $\mathrm{GABA}_{\mathrm{A}} \mathrm{R}$ function under physiological conditions but is reduced in $o b / o b$ and $d b / d b$ mice (in which underlying GABA $_{A} \mathrm{R}$ function and sensitivity are otherwise unchanged). Thus, in neuropathic pain associated with diabetes, neurosteroid levels may be reduced, which contrasts to inflammatory pain, where neurosteroid levels may be upregulated (Poisbeau et al., 2005).

With reference to neurosteroidogenesis in the diabetic mice, incubation treatment with progesterone produced a modest prolongation of $\mathrm{GABA}_{\mathrm{A}} \mathrm{R}$ mIPSC decay time in $o b / o b$ mice that was similar to WT controls and was not concentration-dependent from 1-50 $\mu \mathrm{M}$. Additional recordings made at the highest progesterone concentration in $d b / d b$ mice were no different to those of the WT or $o b / o b$. This suggests that enzymatic function responsible for the endogenous synthesis of allopregnanolone is intact in $o b / o b$ and $d b / d b$. Indeed, due to the shorter baseline decay time of mIPSCs of $o b / o b$ and $d b / d b$ mice, progesterone actually had a proportionately greater effect in the diabetic mice than in WT controls. In keeping with what had been observed in the WT, incubation treatment with finasteride ( $5 \alpha-\mathrm{R}$ inhibitor) also had no effect on $o b / o b$ mIPSCs directly, but was able to block the effect of progesterone in $o b / o b$ mice.

Incubation treatment with DHP (the progesterone metabolite) produced a significant, concentration-dependent prolongation of $\mathrm{GABA}_{\mathrm{A}} \mathrm{R}$ mIPSC decay time that was exaggerated in diabetic mice compared to WT. This finding suggests that not only is $3 \alpha-\mathrm{HSD}$ enzymatic function preserved in mature T2DM mice, but it may actually be upregulated. A potential increase in $3 \alpha-H S D$ activity could be a partial compensation for a reduced baseline endogenous 
neurosteroid tone in diabetic mice. In keeping with what had been observed in WT mice, pipette-applied DHP had no effect on the $o b / o b$ mIPSCs. The lack of effect of DHP is consistent with DHP's role as a metabolic precursor to the active compound allopregnanolone.

Ganaxolone incubation treatment also had a greater impact in $o b / o b$ mice compared with WT, despite the compound being considered previously to be more metabolically stable (Carter et al., 1997). This finding permits the possibility that ganaxolone may potentially be demethylated to allopregnanolone in order to exert maximal effect on cortical GABA Rs. The idea of ganaxolone as both an agonist and precursor to allopregnanolone would also be consistent with the relatively larger effect of ganaxolone incubation in $o b / o b$ mice, which may exhibit an upregulation of key enzymes such as CYP2C and $3 \alpha-H S D$. The inhibitory effect of indometacin on ganaxolone incubation treatment is also consistent with the notion of ganaxolone as an active precursor of allopregnanolone. Indeed, indometacin had no impact on $o b / o b$ cortical neurons when present in the pipette or after 2 hours of incubation treatment. When indometacin and ganaxolone were co-applied within the pipette, indometacin had no impact on the ability of ganaxolone to prolong mIPSCs. The CYP2C subfamily of enzymes is known to metabolise neurosteroids (McFadyen et al., 1998; Miksys \& Tyndale, 2002) and cholesterol is metabolised to pregnenolone by CYP450scc (Miksys \& Tyndale, 2002; Schumacher et al., 2012). Therefore, one possible explanation for this is that indometacin could compete with ganaxolone for the demethylating effects of CYP2C9, however, it must be noted that indometacin may have other non-specific effects.

The underlying mechanism responsible for the reduced neurosteroid tone in the diabetic mice is uncertain, but may be due to mitochondrial dysfunction (Chowdhury et al., 2013; Edwards et al., 2008; Fernyhough et al., 2010; Vincent et al., 2010). It has been postulated that hyperglycaemia has several detrimental effects including the excessive donation of electrons to the mitochondrial electron transport chain, which induces an increased production of reactive oxygen species. The increased availability of electrons may lead to the partial reduction of oxygen to neurotoxic superoxide radicals (Chowdhury et al., 2013; Fernyhough et al., 2010; Vincent et al., 2010). Mitochondrial dysfunction could also account for both mechanical hypersensitivity associated with a reduction in mitochondrial-derived neurosteroids and also for thermal hyposensitivity associated with axonal degeneration (Chowdhury et al., 2013; Drel et al., 2006; Latham et al., 2009; Vincent et al., 2010). The mechanisms of mitochondrial dysfunction in diabetic neuropathy has been covered by other authors (Chowdhury et al., 2013; Fernyhough et al., 2010; Vincent et al., 2010). These data are consistent with the possibility that neurosteroidogenic enzyme function may be upregulated in the $o b / o b$ mice.

The behavioural work was consistent with the known phenotype of the ob/ob (Drel et al., 2006; Mayers et al., 2009) and translated the electrophysiological findings into measurable anti-nociceptive effects. The polyneuropathy phenotype with seemingly paradoxical mechanical hypersensitivity and thermal hyposensitivity is in fact consistent with the progressive diabetic neuropathy observed in the literature (Cefalu, 2006; Drel et al., 2006; Kaplan \& Wagner, 2006;
Latham et al., 2009). The mechanical hypersensitivity of $o b / o b$ mice and the increased response to ganaxolone reflected the observed electrophysiological findings. $\mathrm{Ob} / \mathrm{ob}$ mice developed obesity and T2DM on a normal diet, which led to painful neuropathy by the age of P60-75. At this age they exhibited sensorimotor impairment, thermal hypoalgesia, cold allodynia and mechanical allodynia. In WT mice, the neuroactive steroid ganaxolone impaired sensorimotor function at $30 \mathrm{mg} / \mathrm{kg}$, but the lower dose of $10 \mathrm{mg} / \mathrm{kg}$ did not, and was analgesic for thermal and mechanical nociceptive pain. The effect of ganaxolone on thermal nociception and sensorimotor impairment could not be tested on $o b / o b$ mice due to their preexisting deficits. However, ganaxolone significantly reduced mechanical allodynia in $o b / o b$ mice. These results suggest that $\mathrm{GABA}_{\mathrm{A}} \mathrm{R}$-modulatory neurosteroidal drugs such as ganaxolone may have analgesic properties for nociceptive pain and also neuropathic pain by restoration of the depressed endogenous neurosteroid tone.

\section{Data and software availability}

Open Science Framework: Dataset of 'Neurosteroids are reduced in diabetic neuropathy and may be associated with the development of neuropathic pain', doi: 10.17605/osf.io/bk3tw (Humble, 2016).

Analysed raw data can be found in the supplementary tables (See Supplementary material).

Please refer to Methods section for details of standard software used for data analysis.

\section{Author contributions}

Dr Stephen Humble is responsible for this all work, including planning the experiments, performing the experiments and writing the paper. Prof Hales, Lambert and Dr Belelli assisted Dr Humble with regards to planning many of the experiments. However, after discussion it was decided that their contributions merited being listed in the acknowledgements section rather than as co-authors.

\section{Competing interests}

No competing interests were disclosed.

\section{Grant information}

This research was supported by the Wellcome Trust (Grant No. 090667).

The funders had no role in study design, data collection and analysis, decision to publish, or preparation of the manuscript

\section{Acknowledgements}

I am indebted to the generous support of the Wellcome Trust and would also like to thank: Prof Hales, Dr Belelli, Dr McCrimmon, Prof Peters, Prof Sillar, Dr Connolly, Dr Miles, Prof Poisbeau, Prof Lambert for their scientific advice, Miss Gallacher, Miss Wright, Dr McLeod, Mr McLeod, Dr Newman, Dr Cooper, Dr Brown, Dr Panetta, Dr Livesey for their technical assistance, Prof Matthews, Dr Moffat, Mr F Kafka, Prof P Anand, Dr P Donatien, Dr R Privitera, Dr Y Yangou, Prof A Dickenson, Dr Platt, Dr Ladas, Dr Jenner, Dr Feynman, Mrs E Humble for their support. 


\section{Supplementary material}

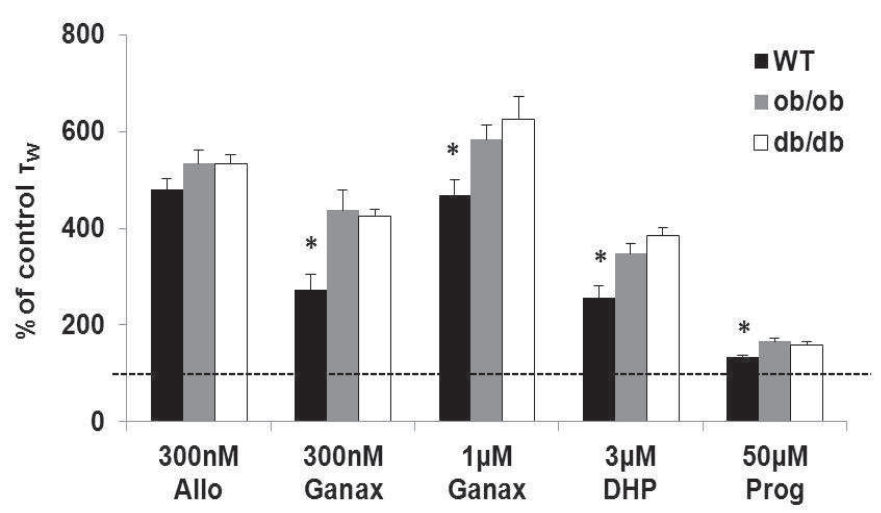

Figure S1. Relative differences in the potencies of certain neurosteroidal compounds. Histogram summarising the relative differences in the potencies of certain neurosteroidal compounds (allopregnanolone, ganaxolone, DHP and progesterone) in three strains of mice (WT, $o b / o b$ and $d b / d b)$ after $\sim 2$ hours brain-slice exposure. When the mIPSC $\tau_{w}$ were normalised for comparison, allopregnanolone and ganaxolone, which modulate the $\mathrm{GABA}_{\mathrm{A}} \mathrm{R}$ directly, have the greatest potency, while the neurosteroid precursors DHP and progesterone have the least potency. There is no significant difference in the effect of allopregnanolone on the three strains of mice $(n=6-9, P>0.05)$. In contrast, the precursor DHP had a greater impact on the diabetic mice $n=8-10$; One-way RM ANOVA $P<0.05$. Post hoc Newman Keul's test revealed significant differences between the WT and both types of diabetic mice, ${ }^{\star} P<0.05$, but there was no intergroup difference between the ob/ob and $d b / d b$ mice, $P>0.05$ ). The precursor progesterone, also had a greater impact on the diabetic mice, $\mathrm{n}=6-12$; One-way RM ANOVA $P<$ 0.05. Post hoc Newman Keul's test revealed significant differences between the WT and both types of diabetic mice, $P<0.05$, but there was no intergroup difference between the $o b / o b$ and $d b / d b$ mice, $P>0.05)$. Ctrl = control; Allo = allopregnanolone; Ganax = ganaxolone; $\mathrm{DHP}=$ dihydroxyprogesterone; Prog = progesterone. 

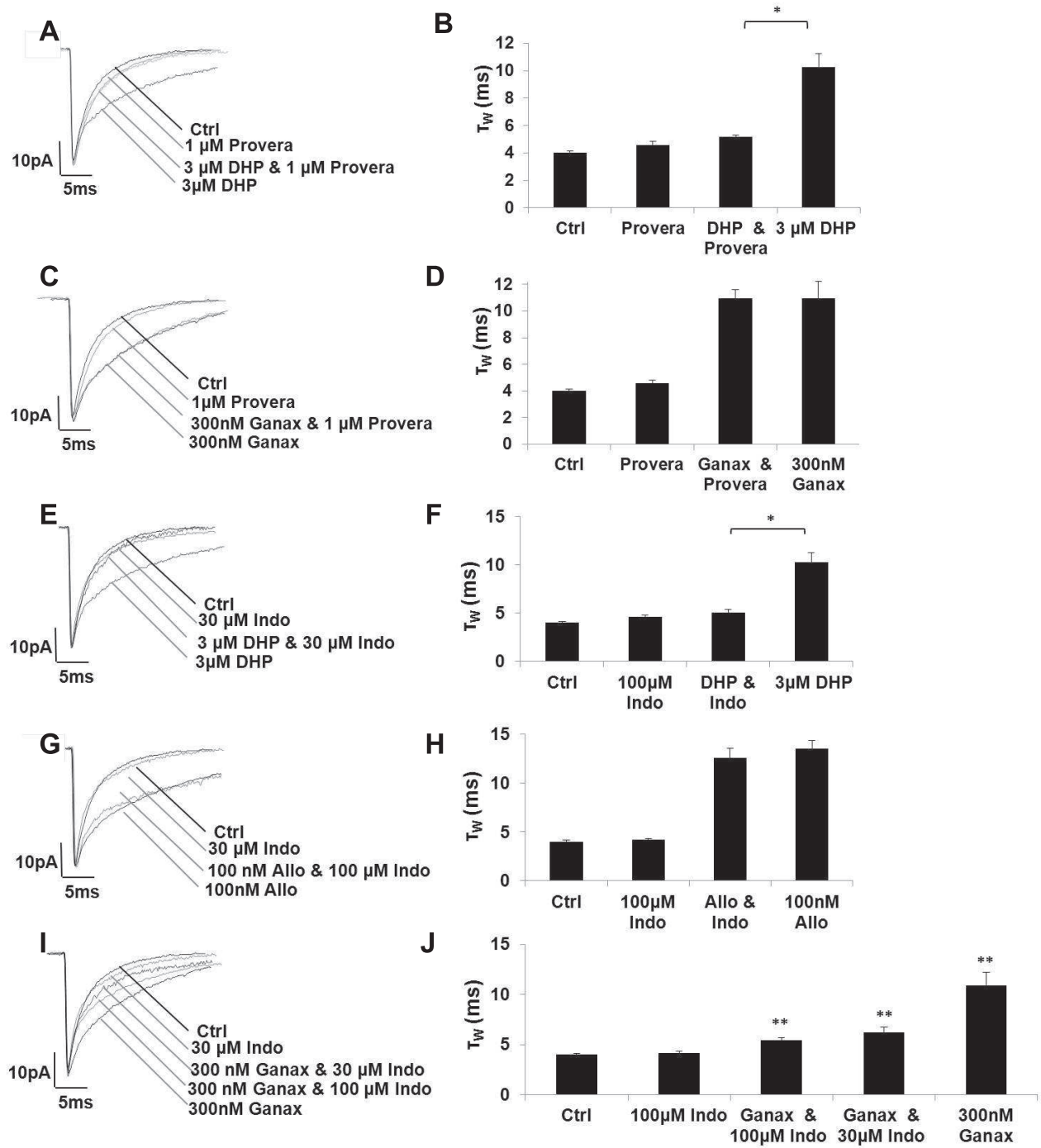

Figure S2. The $3 \alpha$-HSD enzyme inhibitor provera suppresses the effects of DHP, but not ganaxolone on GABA R-mediated mIPSCs of mature cortical neurons. The 3 $\alpha$-HSD enzyme inhibitor indometacin suppresses the effects of DHP and ganaxolone, but not those of allopregnanolone on GABA $\mathbf{R}$-mediated mIPSCs of mature cortical neurons. (A) Superimposed exemplar averaged GABA $\mathrm{R}$ mIPSCs from a representative control cortical neuron and from equivalent neurons after $\sim 2$ hour pre-incubation of the brain slice with provera (1 $\mu \mathrm{M})$, DHP $(3 \mu \mathrm{M})$, or both. To facilitate comparison of their kinetics, the amplitude of the mIPSCs are normalised to that of the control averaged

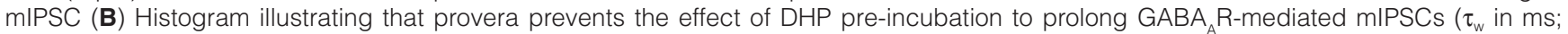
one-way ANOVA $P<0.05$. Post hoc Newman Keul's test revealed differences for DHP $(3 \mu \mathrm{M})$ with or without provera $(1 \mu \mathrm{M})$, ${ }^{*} P<0.05, \mathrm{n}=$ 7-9). (C) Superimposed exemplar averaged GABA $\mathrm{A}_{\mathrm{A}}$ mIPSCs from a representative control cortical neuron and from equivalent neurons after $\sim 2$ hour pre-incubation of the brain slice with provera $(1 \mu \mathrm{M})$, ganaxolone $(300 \mathrm{nM})$, or both. (D) Histogram illustrating that provera did not prevent the effect of ganaxolone on the duration of GABA $\mathrm{R}$ mIPSCs $\left(\tau_{\mathrm{w}}\right.$ in ms; one-way ANOVA $P<0.05$. Post hoc Newman Keul's test revealed no difference for the effects of ganaxolone (300 $\mathrm{nM}$ ) with, or without provera $(1 \mu \mathrm{M}), P>0.05, \mathrm{n}=7-10)$. (E) Superimposed exemplar averaged GABA $R$ mIPSCs acquired from a representative control cortical neuron and from equivalent neurons after $\sim 2$ hours pre-incubation of the brain slice with indometacin $(30 \mu \mathrm{M})$, DHP $(3 \mu \mathrm{M})$, or both. $(\mathbf{F})$ Histogram illustrating that indometacin prevents the effect of DHP on the duration of the GABA ${ }_{A}$ m mIPSCs ( $\tau_{w}$ in ms, one-way ANOVA $P<0.05$. Post hoc Newman Keul's test revealed differences for DHP $3 \mu M$ with or without indometacin $100 \mu \mathrm{M},{ }^{*} P<0.05, \mathrm{n}=6-9$ ). (G) Superimposed exemplar averaged GABA $\mathrm{R}$ mIPSCs acquired from a representative control neuron and from equivalent neurons after an $\sim 2$ hour pre-incubation of the brain slice with indometacin (100 $\mu \mathrm{M})$, allopregnanolone (100 $\mathrm{nM}$ ), or both. $(\mathbf{H})$ Histogram illustrating that indometacin does not prevent the effect of allopregnanolone to prolong the duration of the GABA $_{A}$ R-mediated mIPSC $\left(\tau_{w}\right.$ in ms, one-way ANOVA $P>0.05$. Post hoc Newman Keul's test revealed no differences for allopregnanolone with or without indometacin, $P>0.05, \mathrm{n}=7-9$ ). (I) Superimposed exemplar averaged GABA $\mathrm{R}$ mIPSCs acquired from a representative control neuron and from equivalent neurons after $\sim 2$ hour incubation of the brain slice with indometacin (100 $\mu \mathrm{M})$, ganaxolone (300 $\mathrm{nM})$, or both. (J) Histogram illustrating that indometacin in a concentration-dependant manner $(30-100 \mu \mathrm{M})$ prevents the effect of ganaxolone to prolong the GABA R-mediated mIPSC ( $\tau_{w}$ in ms; one-way ANOVA $P<0.05$. Post hoc Newman Keul's test revealed differences for ganaxolone $300 \mathrm{nM}$ with or without indometacin $30-100 \mu \mathrm{M},{ }^{* \star} P<0.05, \mathrm{n}=8-10$. Ctrl = control; Allo = allopregnanolone; Ganax = ganaxolone; DHP = dihydroxyprogesterone; Indo = indometacin. 
A
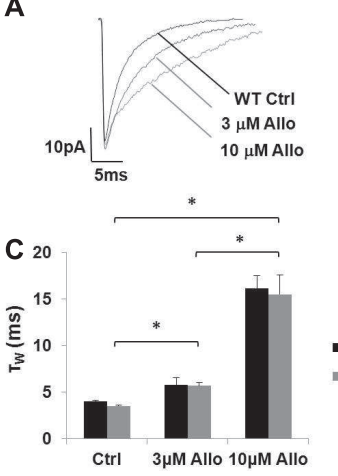

E

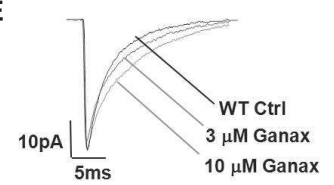

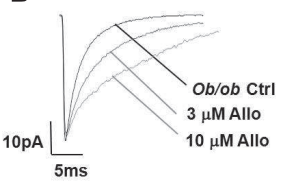
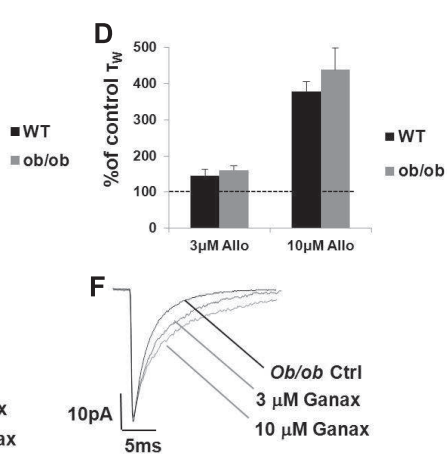

H
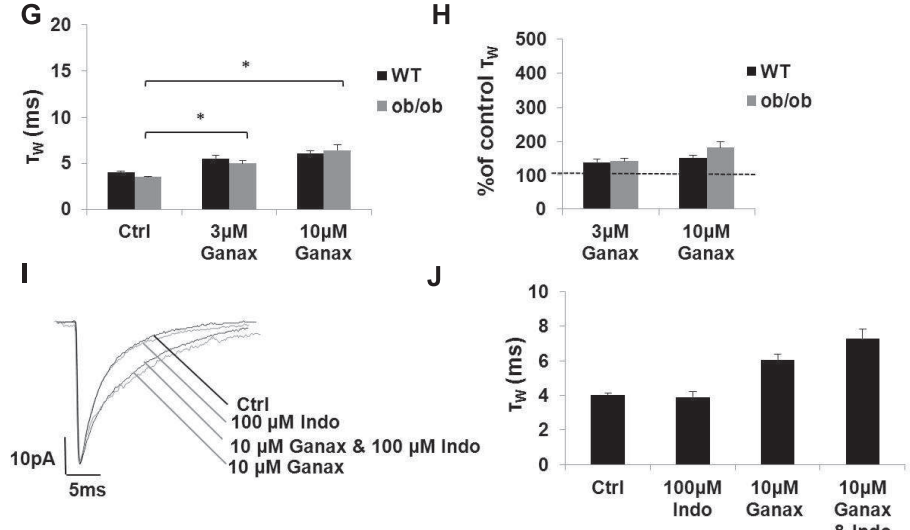

$\mathbf{K}$

$\mathbf{L}$
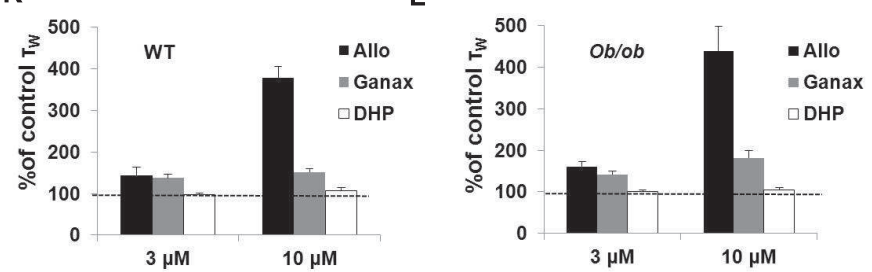

Figure S3. The intracellular application of allopregnanolone or ganaxolone to mature cortical neurons enhances synaptic GABA ${ }_{A}$ function by a similar margin in WT and ob/ob mice. The 3a-HSD enzyme inhibitor indometacin does not suppress the acute effects of intracellularly applied ganaxolone on GABA $_{A} R$ mIPSCs of mature cortical neurons (in contrast to its inhibitory effect on ganaxolone incubation treatment). (A \& B) Superimposed exemplar GABA R mIPSCs from a representative control WT and ob/ob cortical neurons and from equivalent neurons with $3-10 \mu \mathrm{M}$ allopregnanolone administered intracellularly. (C) Histogram illustrating the concentration-dependent effect of the intracellular application of allopregnanolone on the duration of GABA Rs mIPSC $\tau$ in WT and ob/ob cortical neurons ( $n=5-25$; One-way ANOVA $\left.{ }^{*} P<0.05\right)$. (D) Histogram illustrating the concentration-dependent effect of allopregnanolone on the duration of GABA Rs mIPSC $\tau$ of WT (black) and ob/ob cortical neurons (grey) expressed as a percentage of control. There was no significant difference in the effect of allopregnanolone on WT $v s$. ob/ob cortical GABA Rs mIPSCs ( $n=5-7$; One-way RM ANOVA $P>0.05$ ). (E \& F) Superimposed exemplar GABA Rs mIPSCs from a representative control WT and ob/ob cortical neurons and from equivalent neurons with 3-10 $\mu \mathrm{M}$ ganaxolone administered intracellularly. (G) Histogram illustrating the concentration-dependent effect of the intracellular application of ganaxolone on the duration of GABA $A_{A}$ s mIPSC $\tau_{w}$ in WT and ob/ob cortical neurons $(n=6-25$; One-way ANOVA * $P<0.05)$. (H) Histogram illustrating the concentration-dependent effect of ganaxolone on the duration of GABA Rs mIPSC $\tau$ of WT (black) and ob/ob cortical neurons (grey) expressed as a percentage of control. There was no significant difference in the effect of ganaxolone on WT vs. ob/ob cortical GABA Rs mIPSCs ( $n=6$; One-way RM ANOVA $P>0.05)$. (I) Superimposed exemplar averaged GABA R-mediated mIPSCs acquired from a representative control mature L2/3 cortical neuron and from equivalent neurons after the intracellular application of ganaxolone $(10 \mu \mathrm{M})$, indometacin $(100 \mu \mathrm{M})$ or both. $(\mathbf{J})$ Histogram illustrating that intracellular indometacin made no impact on the effectiveness of intracellular ganaxolone (Student's unpaired t tests $P>0.05$ for ganaxolone $10 \mu \mathrm{M}$ vs. ganaxolone $10 \mu \mathrm{M}$ with indometacin $100 \mu \mathrm{M}, \mathrm{n}=4-6$ ). (K \& L) Histograms illustrating the lack of effect of the intracellular application of 3-10 $\mu \mathrm{M}$ DHP (white bars) on the duration of WT and ob/ob cortical GABA $A_{A}$ s mIPSC $\tau_{w}$ (One-way ANOVA $P>0.05$ ) in contrast to the effectiveness of allopregnanolone and ganaxolone. Ctrl = control; Allo = allopregnanolone; Ganax = ganaxolone; DHP = dihydroxyprogesterone. 
Additional material

Click here to access the data.

Supplementary tables

Click here to access the data.

Agis-Balboa RC, Pinna G, Zhubi A, et al:: Characterization of brain neurons that express enzymes mediating neurosteroid biosynthesis. Proc Natl Acad Sci U S A. 2006; 103(39): 14602-7.

PubMed Abstract | Publisher Full Text | Free Full Text

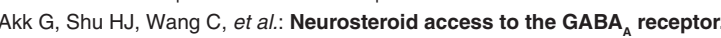
J Neurosci. 2005; 25(50): 11605-13.

PubMed Abstract | Publisher Full Text

Arcelli $\mathrm{P}$, Frassoni $\mathrm{C}$, Regondi MC, et al:: GABAergic neurons in mammalian thalamus: a marker of thalamic complexity? Brain Research Bulletin. 1997; 42(1): 27-37.

PubMed Abstract | Publisher Full Text

Asiedu MN, Mejia G, Ossipov MK, et al:: Modulation of spinal GABAergic analgesia by inhibition of chloride extrusion capacity in mice. J Pain. 2012; 13(6): 546-554.

PubMed Abstract | Publisher Full Text | Free Full Text

Bates SH, Kulkarni RN, Seifert M, et al:: Roles for leptin receptor/STAT3-dependent and -independent signals in the regulation of glucose homeostasis. Cell Metab. 2005; 1(3): 169-73

PubMed Abstract | Publisher Full Text

Belelli D, Herd MB: The contraceptive agent Provera enhances GABA receptormediated inhibitory neurotransmission in the rat hippocampus: evidence for endogenous neurosteroids? J Neurosci. 2003; 23(31): 10013-20.

PubMed Abstract

Benkwitz C, Liao M, Laster MJ, et al: Determination of the $\mathrm{EC}^{50}$ amnesic concentration of etomidate and its diffusion profile in brain tissue: implications for in vitro studies. Anesthesiology. 2007: 106(1): 114-23.

PubMed Abstract | Publisher Full Tex

Besheer J, Linsay TG, O'Buckley TK, et al:: Pregnenolone and ganaxolone reduce operant ethanol self-administration in alcohol-preferring $p$ rats. Alcohol Clin Exp Res. 2010; 34(12): 2044-52.

PubMed Abstract | Publisher Full Text | Free Full Text

Brown AR, Herd MB, Belelli D, et al.: Developmentally regulated neurosteroid synthesis enhances GABAergic neurotransmission in mouse thalamocortical neurones. J Physiol. 2015; 593(1): 267-284.

PubMed Abstract | Publisher Full Text | Free Full Text

Callachan $\mathrm{H}$, Cottrell GA, Hather NY, et al:: Modulation of the GABA receptor by progesterone metabolites. Proc $R$ Soc Lond B Biol Sci. 1987; 231(1264): 359-69. PubMed Abstract | Publisher Full Tex

Carter RB, Wood PL, Wieland S, et al:: Characterization of the anticonvulsan properties of ganaxolone (CCD 1042; 3alpha-hydroxy-3beta-methyl-5alphapregnan-20-one), a selective, high-affinity, steroid modulator of the gammaaminobutyric acid(A) receptor. J Pharmacol Exp Ther. 1997; 280(3): 1284-95. PubMed Abstract

Cefalu WT: Animal models of type 2 diabetes: clinical presentation and pathophysiological relevance to the human condition. ILAR J. 2006; 47(3): 186-98.

PubMed Abstract | Publisher Full Tex

Chen SR, Pan HL: Hypersensitivity of spinothalamic tract neurons associated with diabetic neuropathic pain in rats. J Neurophysiol. 2002; 87(6): 2726-33. PubMed Abstract

Chen $\mathrm{H}$, Charlat O, Tartaglia LA, et al.: Evidence that the diabetes gene encodes the leptin receptor: identification of a mutation in the leptin receptor gene in db/db mice. Cell. 1996; 84(3): 491-5.

PubMed Abstract | Publisher Full Text

Chisari M, Eisenman LN, Krishnan K, et al: The influence of neuroactive steroid lipophilicity on $\mathrm{GABA}_{A}$ receptor modulation: evidence for a low-affinity interaction. J Neurophysiol. 2009; 102(2): 1254-64

PubMed Abstract | Publisher Full Text | Free Full Text

Chowdhury SK, Smith DR, Fernyhough P: The role of aberrant mitochondrial bioenergetics in diabetic neuropathy. Neurobiol Dis. 2013; 51: 56-65.

PubMed Abstract | Publisher Full Tex

Chung WK, Power-Kehoe L, Chua M, et al:: Genomic structure of the human $\mathrm{OB}$ receptor and identification of two novel intronic microsatellites. Genome Res.
1996; 6(12): 1192-9

PubMed Abstract | Publisher Full Tex

Clascá F, Rubio-Garrido P, Jabaudon D: Unveiling the diversity of

thalamocortical neuron subtypes. Eur J Neurosci. 2012; 35(10): 1524-32.

PubMed Abstract | Publisher Full Text

Cooper A, Nutley M, MacLean EJ, et al:: Mutual induced fit in cyclodextrinrocuronium complexes. Org Biomol Chem 2005; 3(10): 1863-71. PubMed Abstract | Publisher Full Text

Cox CL, Huguenard JR, Prince DA: Nucleus reticularis neurons mediate diverse inhibitory effects in thalamus. Proc Natl Acad Sci U S A. 1997; 94(16): 8854-9. PubMed Abstract | Publisher Full Text | Free Full Text

D'Amour FE, Smith DL: A method for determining loss of pain sensation. $J$ Pharmacol Exp Ther. 1941; 72: 74-9.

Reference Sourc

D'Hulst C, Atack JR, Kooy RF: The complexity of the GABA receptor shapes unique pharmacological profiles. Drug Discov Today. 2009; 14(17-18):866-75. PubMed Abstract | Publisher Full Text

Danaei G, Finucane MM, Lu Y, et al: National, regional, and global trends in fasting plasma glucose and diabetes prevalence since 1980: systematic analysis of health examination surveys and epidemiological studies with 370 country-years and 2.7 million participants. Lancet. 2011; 378(9785): 31-40. PubMed Abstract | Publisher Full Text

Davis ME, Brewster ME: Cyclodextrin-based pharmaceutics: past, present and future. Nat Rev Drug Discov. 2004; 3(12): 1023-35.

PubMed Abstract | Publisher Full Text

DeFelipe J, Fariñas I: The pyramidal neuron of the cerebral cortex:

morphological and chemical characteristics of the synaptic inputs. Prog

Neurobiol 1992; 39(6): 563-607.

PubMed Abstract | Publisher Full Text

Drel VR, Mashtalir N, Ilnytska O, et al:: The leptin-deficient (ob/ob) mouse: a new animal model of peripheral neuropathy of type 2 diabetes and obesity. Diabetes. 2006. 55(12): 3335-43.

PubMed Abstract | Publisher Full Text

Edwards JL, Vincent AM, Cheng HT, et al:: Diabetic neuropathy: mechanisms to management. Pharmacol Ther. 2008; 120(1): 1-34.

PubMed Abstract | Publisher Full Text | Free Full Text

Evans MG, Marty A: Potentiation of muscarinic and alpha-adrenergic responses by an analogue of guanosine 5'-triphosphate. Proc Natl Acad Sci U S A. 1986; 83(11): 4099-103.

PubMed Abstract | Free Full Text

Fernyhough P, Roy Chowdhury SK, Schmidt RE: Mitochondrial stress and the pathogenesis of diabetic neuropathy. Expert Rev Endocrinol Metab. 2010; 5(1): 39-49.

PubMed Abstract | Publisher Full Text | Free Full Text

Flor H, Bushnell MC: Central imaging of pain. In Hunt S, Koltzenburg M, eds. The neurobiology of pain. Oxford: Oxford University Press, 2005; 311-32. Publisher Full Text

Gentet LJ, Ulrich D: Strong, reliable and precise synaptic connections between thalamic relay cells and neurones of the nucleus reticularis in juvenile rats. J Physiol. 2003; 546(Pt 3): 801-11.

PubMed Abstract | Publisher Full Text | Free Full Text

Gredell JA, Turnquist PA, Maciver MB, et al: Determination of diffusion and partition coefficients of propofol in rat brain tissue: implications for studies of drug action in vitro. Br J Anaesth. 2004; 93(6): 810-7.

PubMed Abstract | Publisher Full Text

Guillery RW, Harting JK: Structure and connections of the thalamic reticula nucleus: Advancing views over half a century. J Comp Neurol. 2003; 463(4): $360-71$

PubMed Abstract | Publisher Full Text

Hosie AM, Wilkins ME, da Silva HM, et al.: Endogenous neurosteroids regulate GABA receptors through two discrete transmembrane sites. Nature. 2006; 444(7118): 486-489.

PubMled Abstract | Publisher Full Text 
Huh Y, Bhatt R, Jung D, et al:: Interactive responses of a thalamic neuron to formalin induced lasting pain in behaving mice. PLOS One. 2012; 7(1): e30699. PubMed Abstract | Publisher Full Text | Free Full Text

Humble SR: Dataset of 'Neurosteroids are reduced in diabetic neuropathy and may be associated with the development of neuropathic pain'. Open Science Framework. 2016.

Data Source

Johnston GA: GABAA receptor channel pharmacology. Curr Pharm Des. 2005;

11(15): $1867-85$

PubMed Abstract | Publisher Full Text

Jones BJ, Roberts DJ: The quantiative measurement of motor inco-ordination in naive mice using an acelerating rotarod. J Pharm Pharmacol. 1968; 20(4): 302-4. PubMed Abstract | Publisher Full Text

Kaplan JR, Wagner JD: Type 2 diabetes-an introduction to the development and use of animal models. ILAR J. 2006; 47(3): 181-5.

PubMed Abstract | Publisher Full Tex

Keller AF, Coull JA, Chery N, et al.: Region-specific developmental specialization of GABA-glycine cosynapses in laminas I-II of the rat spinal dorsal horn. $J$ Neurosci. 2001; 21(20): 7871-80.

PublMed Abstract

Keller AF, Breton JD, Schlichter R, et al:: Production of 5alpha-reduced neurosteroids is developmentally regulated and shapes GABA $_{A}$ miniature IPSCs in lamina II of the spinal cord. J Neurosci. 2004; 24(4): 907-15. PubMed Abstract | Publisher Full Text

Knabl J, Witschi R, Hösl K, et al.: Reversal of pathological pain through specific spinal GABA ${ }_{A}$ receptor subtypes. Nature. 2008; 451(7176): 330-4.

PubMed Abstract | Publisher Full Text

Lambert JJ, Cooper MA, Simmons RD, et al:: Neurosteroids: endogenous allosteric modulators of $\mathrm{GABA}_{\mathrm{A}}$ receptors. Psychoneuroendocrinology. 2009; 34(Suppl 1): S48-S58.

PubMed Abstract | Publisher Full Text

Latham JR, Pathirathna S, Jagodic MM, et al.: Selective T-type calcium channel blockade alleviates hyperalgesia in ob/ob mice. Diabetes. 2009; 58(11): 2656-65.

PubMed Abstract | Publisher Full Text | Free Full Text

Li P, Shu HJ, Wang C, et al.: Neurosteroid migration to intracellular compartments reduces steroid concentration in the membrane and diminishes GABA-A receptor potentiation. J Physiol. 2007; 584(Pt 3): 789-800.

PubMed Abstract | Publisher Full Text | Free Full Text

Lindström P: The physiology of obese-hyperglycemic mice [ob/ob mice].

ScientificWorld Journal. 2007: 7: 666-85.

PubMed Abstract | Publisher Full Tex

Lübke J, Feldmeyer D: Excitatory signal flow and connectivity in a cortical column: focus on barrel cortex. Brain Struct Funct. 2007; 212(1): 3-17.

PubMed Abstract | Publisher Full Text

Maguire EP, Macpherson T, Swinny JD, et al.: Tonic inhibition of accumbal spiny neurons by extrasynaptic $\alpha 4 \beta \delta \mathrm{GABA}_{\mathrm{A}}$ receptors modulates the actions of psychostimulants. J Neurosci. 2014; 34(3): 823-838.

PubMed Abstract | Publisher Full Text | Free Full Text

Mayers JR, lliff BW, Swoap SJ: Resveratrol treatment in mice does not elicit the bradycardia and hypothermia associated with calorie restriction. FASEB 2009; 23(4): 1032-40.

PubMed Abstract | Publisher Full Text | Free Full Text

McFadyen MC, Melvin WT, Murray GI: Regional distribution of individual forms of cytochrome P450 mRNA in normal adult human brain. Biochem Pharmacol. 1998; 55(6): 825-30.

PubMed Abstract | Publisher Full Tex

Mensah-Nyagan AG, Meyer L, Schaeffer V, et al.: Evidence for a key role of steroids in the modulation of pain. Psychoneuroendocrinology. 2009; 34(Suppl 1): S169-S177.

PubMed Abstract | Publisher Full Tex

Merskey H, Bogduk N: Classification of Chronic Pain. Descriptions of Chronic Pain Syndromes and Definitions of Pain Terms. Seattle: IASP Press, 1994. Reference Source

Meyer HS, Schwarz D, Wimmer VC, et al: Inhibitory interneurons in a cortical column form hot zones of inhibition in layers 2 and 5 A. Proc Natl Acad Sci U S A. 2011; 108(40): 16807-12.

PubMed Abstract | Publisher Full Text | Free Full Text

Meyer L, Patte-Mensah C, Taleb O, et al: Allopregnanolone prevents and suppresses oxaliplatin-evoked painful neuropathy: multi-parametric assessment and direct evidence. Pain 2011:152(1): 170-81.

PubMed Abstract | Publisher Full Text

Meyer L, Patte-Mensah C, Taleb $\mathrm{O}$, et al: Cellular and functional evidence for a protective action of neurosteroids against vincristine chemotherapy-induced painful neuropathy. Cell Mol Life Sci. 2010; 67(17): 3017-34.

PubMed Abstract | Publisher Full Text

Miksys SL, Tyndale RF: Drug-metabolizing cytochrome P450s in the brain.

J Psychiatry Neurosci. 2002; 27(6): 406-15.

PubMed Abstract | Free Full Text

Mitchell EA, Gentet LJ, Dempster J, et al.: GABA and glycine receptor-mediated transmission in rat lamina II neurones: relevance to the analgesic actions of neuroactive steroids. J Physiol. 2007; 583(Pt 3): 1021-40.

PubMed Abstract | Publisher Full Text | Free Full Text

Mogil JS: Animal models of pain: progress and challenges. Nat Rev Neurosci. 2009; 10(4): 283-94.

PubMed Abstract | Publisher Full Text

Mountcastle VB: The columnar organization of the neocortex. Brain. 1997;

120(Pt 4): 701-22.

PubMed Abstract | Publisher Full Text

Munro G, Ahring PK, Mirza NR: Developing analgesics by enhancing spinal inhibition after injury: GABA receptor subtypes as novel targets. Trends

Pharmacol Sci. 2009; 30(9): 453-9.

PubMed Abstract | Publisher Full Text

Pinault $D$, Deschênes M: Projection and innervation patterns of individual thalamic reticular axons in the thalamus of the adult rat: a three-dimensional, graphic, and morphometric analysis. J Comp Neurol. 1998; 391(2): 180-203. PubMed Abstract | Publisher Full Text

Poisbeau P, Patte-Mensah C, Keller AF, et al.: Inflammatory pain upregulates spinal inhibition via endogenous neurosteroid production. J Neurosci. 2005; 25(50): 11768-76

PubMed Abstract | Publisher Full Text

Pritchett K, Mulder GB: The rotarod. Contemp Top Lab Anim Sci. 2003; 42(6): 49. PubMed Abstract

Rajalu M, Müller UC, Caley A, et al:: Plasticity of synaptic inhibition in mouse spinal cord lamina II neurons during early postnatal development and after inactivation of the glycine receptor alpha3 subunit gene. Eur J Neurosci. 2009; 30(12): 2284-92.

PubMed Abstract | Publisher Full Text

Reddy DS, Rogawski MA: Ganaxolone suppression of behavioral and electrographic seizures in the mouse amygdala kindling model. Epilepsy Res. 2010; 89(2-3): 254-60.

PubMed Abstract | Publisher Full Text | Free Full Text

Sanna E, Talani G, Busonero F, et al.: Brain steroidogenesis mediates ethano modulation of GABA receptor activity in rat hippocampus. $J$ Neurosci. 2004; 24(29): 6521-6530.

PubMed Abstract | Publisher Full Tex

Schlichter R, Keller AF, De Roo M, et al: Fast nongenomic effects of steroids on synaptic transmission and role of endogenous neurosteroids in spinal pain pathways. J Mol Neurosci. 2006; 28(1): 33-51.

PubMed Abstract | Publisher Full Text

Schumacher M, Hussain R, Gago N, et al.: Progesterone synthesis in the nervous system: implications for myelination and myelin repair. Front Neurosci. 2012; 6: 10 . PubMed Abstract | Publisher Full Text | Free Full Text

Shu HJ, Eisenman LN, Jinadasa D, et al.: Slow actions of neuroactive steroids at GABAA receptors. J Neurosci. 2004; 24(30): 6667-75.

PubMed Abstract | Publisher Full Text

Shu HJ, Zeng CM, Wang C, et al.: Cyclodextrins sequester neuroactive steroids and differentiate mechanisms that rate limit steroid actions. Br J Pharmacol. 2007; 150(2): 164-75.

PubMed Abstract | Publisher Full Text | Free Full Text

Solovyova N, Moult PR, Milojkovic B, et al.: Bi-directional modulation of fast inhibitory synaptic transmission by leptin. J Neurochem. 2009; 108(1): 190-201. PubMed Abstract | Publisher Full Text | Free Full Text

Stein DG: Progesterone exerts neuroprotective effects after brain injury. Brain Res Rev. 2008; 57(2): 386-97.

PubMed Abstract | Publisher Full Text | Free Full Text

Stoffel-Wagner B: Neurosteroid biosynthesis in the human brain and its clinical implications. Ann NY Acad Sci. 2003; 1007: 64-78.

PubMed Abstract | Publisher Full Text

Sullivan KA, Hayes JM, Wiggin TD, et al.: Mouse models of diabetic neuropathy. Neurobiol Dis. 2007; 28(3): 276-85.

PubMed Abstract | Publisher Full Text | Free Full Text

Treede RD, Kenshalo DR, Gracely RH, et al:: The cortical representation of pain. Pain. 1999; 79(2-3): 105-11.

PubMed Abstract | Publisher Full Text

Tsutsui K: Neurosteroids in the Purkinje cell: biosynthesis, mode of action and functional significance. Mol Neurobiol. 2008; 37(2-3): 116-25.

PubMed Abstract | Publisher Full Text

Vareniuk I, Pavlov IA, Drel VR, et al.: Nitrosative stress and peripheral diabetic neuropathy in leptin-deficient (ob/ob) mice. Exp Neurol. 2007; 205(2): 425-36. PubMed Abstract | Publisher Full Text

Vincent AM, Edwards JL, McLean LL, et al:: Mitochondrial biogenesis and fission in axons in cell culture and animal models of diabetic neuropathy. Acta Neuropathol. 2010: 120(4): 477-89.

PubMed Abstract | Publisher Full Text | Free Full Text

von Hehn CA, Baron R, Woolf CJ: Deconstructing the neuropathic pain phenotype to reveal neural mechanisms. Neuron. 2012; 73(4): 638-52.

PubMed Abstract | Publisher Full Text | Free Full Text

Zeilhofer HU: Loss of glycinergic and GABAergic inhibition in chronic paincontributions of inflammation and microglia. Int Immunopharmacol. 2008; 8(2): 182-7.

PubMed Abstract | Publisher Full Text 


\section{Open Peer Review}

\section{Current Peer Review Status: ? $\checkmark$}

\section{Version 1}

Reviewer Report 03 March 2017

https://doi.org/10.5256/f1000research.9720.r20664

(C) 2017 Song $X$ et al. This is an open access peer review report distributed under the terms of the Creative Commons Attribution License, which permits unrestricted use, distribution, and reproduction in any medium, provided the original work is properly cited.

\section{Xue-Jun Song}

Center for Anesthesiology and Pain Medicine, Department of Anesthesiology, Peking University Cancer Hospital and Institute, Beijing , China

Changyu Jiang

Nanshan Hospital, Guangdong, Shenzhen, China

In this manuscript, the author investigated the neural electrophysiological characterizations of the spinal cord, the nucleus reticularis of the thalamus and the cerebral cortex by means of whole-cell patch-clamp recordings. The results suggested that diabetic mice showed reduced neurosteroid tone but enhanced sensitivity to some neurosteroids, ob/ob mice exhibited mechanical hyperalgesia and allodynia, which was reduced by neurosteroids applied exogenously. The author concluded that the reduced endogenous neurosteroid tone in ob/ob mice may be linked to their hypersensitivity.

Questions:

1. The author concluded the loss of neurosteroid tone in ob/ob mice. There is no further mechanism study.

2. What is the neurosteroid receptor expression in ob/ob mice, compared with WT mice? Is there any alternation in diabetic mice?

3. The author did not show the frequency of mIPSC in lamina II of the spinal dorsal horn, nRT and layer $2 / 3$ of the cortex. How about the frequency of mIPSC in those sites with development. Please show some representative consecutive chart recording.

4. According to the results, the amplitude of mIPSC is around $35-40 \mathrm{~Pa}$, which is larger than our experience. Can the author give the reason.

5. Please can the author check the alphabetical sequences of the figures and figure legends.

Competing Interests: No competing interests were disclosed.

We confirm that we have read this submission and believe that we have an appropriate level of expertise to confirm that it is of an acceptable scientific standard, however we have 


\section{significant reservations, as outlined above.}

Author Response 22 Mar 2017

Stephen Humble, Charing Cross Hospital, Imperial College NHS Healthcare Trust London, London, UK

1. Dear Reviewer, thank you for all your comments. This is an excellent point. The next logical step would be to carry out mass spectrometry to compare ob/ob and WT samples from pain pathway tissue. Unfortunately this was beyond the scope of the project.

2. GABA A receptors are the principle targets for the neurosteroid molecules that were investigated in these studies. The difference between ob/ob, $\mathrm{db} / \mathrm{db}$ and WT mice is as follows: ob/ob lack leptin, db/db lack a functional leptin receptor and WT have normal leptin secretion and normal leptin receptor. The leptin receptor is entirely distinct from the GABA A receptor and there are no credible reports of leptin having a significant impact on the GABA A receptor. In anticipation of this question the second type 2 diabetic model $(\mathrm{db} / \mathrm{db})$ was used in order to illustrate that leptin was not implicated in the results. There is no specific reason a priori to consider that the GABA A receptor structure and function would be congenitally different than the WT. Indeed, the diabetic neuropathy happens with advancing maturity- hence why the experiments were carried out in mature animals that had developed neuropathic changes.

The experiments using intracellular cyclodextrin illustrate that when the entire neurosteroid tone is removed by sequestration the baseline GABA A receptor function is the same for all strains of mice including diabetic and WT. Secondly, the application of the active neurosteroid allopregnanolone had the same impact on all strains. Thirdly, the intracellular application of neurosteroids enhanced GABA A receptor function by a similar margin in WT and ob/ob. All these observations taken together appear to be inconsistent with the hypothesis that GABA A receptor sensitivity differs between ob/ob, $\mathrm{db} / \mathrm{db}$ and WT. If the GABA A receptor sensitivity is unchanged between strains this would be consistent with the hypothesis that GABA A receptor expression was not significantly different in the ob/ob, $\mathrm{db} / \mathrm{db}$ and WT.

3. Due to the large amount of data contained within these studies the tables containing information such as the frequency of the MIPSCs are included as supplementary files. They can be accessed on the article's webpage immediately below the Supplementary Material section and immediately above the References section. Any additional material not found there will be found in the author's thesis using the link below:

http://discovery.dundee.ac.uk/portal/en/theses/neurosteroids(c4659466-cd41-494d-aec6edcf50e5274b).html

In general terms, the frequency of mIPSCs increased with development in pain pathway neurons. This was anticipated due to known progressive synaptic development with maturation and was consistent with work from other authors. Specifically, there were no unexpected findings related to frequency with development. In addition, the neurosteroids investigated had no significant, consistent impact on frequency in the neurons studied. For 
these reasons, frequency has not been discussed in depth in the paper despite the fact that the frequency of the mIPSCs was recorded and analyzed routinely as part of the experiments along with other parameters.

4. This is an interesting observation. It is most likely due to differences in the utilization of the electrophysiological equipment and the process of analyzing the mIPSCs. It is not uncommon to observe differences between institutions for these reasons and there are many examples within the international literature. It is worth noting that the parameters such as amplitude, frequency, charge transfer, decay time in control recordings was consistent with recordings made by colleagues within the same institution that were using the same equipment set up and analysis protocols and software. In addition, it is standard established practice within the institution to exclude mIPSCs with a Rise Time greater than 1 millisecond (as mentioned in the Data Analysis section of the Methods). This approach excludes events (which have a longer Rise Time) because they are not immediately adjacent to the synapse. The author notes that the excluded events typically have lower amplitudes and have a morphology less like typical mIPSCs.

5. I have checked and rechecked the alphabetical sequences of the figures and figure legends and unfortunately cannot detect a specific issue. Please indicate which Figures and Figure Legends are the problem and I will correct them.

Competing Interests: None.

Reviewer Report 14 February 2017

https://doi.org/10.5256/f1000research.9720.r19599

(c) 2017 Dickenson A. This is an open access peer review report distributed under the terms of the Creative Commons Attribution License, which permits unrestricted use, distribution, and reproduction in any medium, provided the original work is properly cited.

\section{Anthony H. Dickenson}

Department of Neuroscience, Physiology and Pharmacology, University College London, London, UK

This is an interesting study using electrophysiological and behavioural approaches in strains of mice to gauge the potential changes in neurosteroid signalling in diabetic neuropathy. The study extends through the central nervous system and the data is suggestive of important roles of these substances. The work is detailed and meticulous. However, using in vitro slices cannot allow for investigation of identified neurons in terms of pain inputs and how these may be altered by neurosteroids or indeed, neuropathy. 
Competing Interests: No competing interests were disclosed.

I confirm that I have read this submission and believe that I have an appropriate level of expertise to confirm that it is of an acceptable scientific standard.

Author Response 22 Mar 2017

Stephen Humble, Charing Cross Hospital, Imperial College NHS Healthcare Trust London, London, UK

Dear Reviewer, thank you for all your comments!

Competing Interests: No competing interests were disclosed.

Reviewer Report 15 August 2016

https://doi.org/10.5256/f1000research.9720.r15694

(C) 2016 Connolly C. This is an open access peer review report distributed under the terms of the Creative Commons Attribution License, which permits unrestricted use, distribution, and reproduction in any medium, provided the original work is properly cited.

\section{Christopher Connolly}

Centre for Environmental Change and Human Resilience (CECHR), University of Dundee, Dundee, UK

I am not an electrophysiologist by training but am an expert in GABA(A) receptors.

Summary:

TIID mice have reduced neurosteroid tone but increased sensitivity to some neurosteroids.

Ob/ob mice have mechanical hyperalgesia and allodynia (reduced by neurosteroid application).

Conclusions:

Reduced neurosteroid tone may be linked to hypersensitivity.

Neurosteroids may exert analgesic effects by restoring GABAergic inhibitory tone.

Comments:

1. I'm not clear on the comments relating to a developmental change in tone, yet the comment that this may be due to fluctuations in endogenous neurosteroid tone. I assume the authors do not mean to imply that development also fluctuates. Perhaps this needs rephrasing.

2. Is anything known about the loss of neurosteroid tone? Is it due to altered neurosteroid production/degradation or receptor expression to non-responsive receptors? 
3. Presumably the use of the smaller cyclodextrins excludes the possibility of membrane cholesterol involvement. This should be stated.

4. Has the time required for neurosteroid diffusion in a slice been confirmed using isolated neurons in culture (where no diffusion barrier exists)? This would help distinguish between neurosteroid-induced chronic changes in protein trafficking/gene expression and genuine diffusion if the changes can occur more quickly in culture.

5. Does the lack of finasteride on WT and ob/ob mice indicate that there is no endogenous basal neurosteroid-induced tone? The half-life of neurosteroid should be stated so that it may be considered with regard to being relevant.

6. It is interesting that galaxalone might be an allosteric modulator of GABA(A)Rs (as the other possibility of indomethacin as an antagonist has been excluded).

7. The rotarod test seems unfair when comparing fat mice to WT, but is valid in determining the detrimental effects of high doses of neurosteroid.

8. The effects of ganaxolone on $\mathrm{VF}$ is encouraging to indicate its potential relief from mechanical pain.

9. The possibility of differential binding sites to neurosteroids that could be differentially expressed is worthy of mention.

10. With the evidence presented here, I understand that the effects of Progesterone and DHP are greater in diabetic models, which would support an upregulation of the neurosteroid synthesis pathway as some compensatory mechanism. However, the evidence for the loss of neurosteroid tone remains elusive and probably upstream of the production of progesterone. This would presumably imply a deficit in mitochondrial cholesterol uptake, metabolism to pregnenolone, its efflux into the cytosol, or conversion to progesterone (from here on, the pathway to allopregnanolone is normal or enhanced). This needs to be spelled out more clearly.

Competing Interests: I have provided the author with general advice on GABA(A) receptors in the past, but have not contributed to this study.

I confirm that I have read this submission and believe that I have an appropriate level of expertise to confirm that it is of an acceptable scientific standard, however I have significant reservations, as outlined above.

Author Response 17 Feb 2017

Stephen Humble, Charing Cross Hospital, Imperial College NHS Healthcare Trust London, London, UK

Authors Comments in response to the reviewer 
Thank you very much indeed for talking the time to review the paper

1. The author agrees that development does not fluctuate. Neurosteroid tone starts out very high in the most immature neurons then decreases as with maturity. At around P20 the neurosteroid tone is almost negligible, but a modest neurosteroid tone has reappeared in mature neurones by P60 (Humble 2013, Brown 2012). The presence of the neurosteroid tone may be revealed with the use of cyclodextrin. Separately the overall $\tau_{W}$ of the mIPCs also decreases independently of the neurosteroid tone with progressive maturity (Humble 2013, Brown 2012).

2. Loss of neurosteroid tone in development thought to be due to reduced production. But separately there is also changes in the expression of different receptor subtypes (e.g. alpha2 as per Bosman et al., 2005).

3. I can insert: 'The use of small cyclodextrins was used to attempt to control for the generic effects of cyclodextrin such as an interaction with the cholesterol within the neuronal membrane.'

4.The author had not performed experiments using isolated neurons in culture, nor explored specific potential changes in trafficking/gene expression. The lack of these experiments could be considered a relative limitation of the study and would be a useful complimentary study. The author used different methods of neurosteroid presentation in order to explore the issue of diffusion and ensure that neurosteroid penetration of the slice was optimal in each situation. In order to maximize the neurosteroid effect the slices were incubated more than an hour with the relevant neurosteroid compound as per work on other lipophilic GABAergic compounds by other authors (Benkwitz et al., 2007; Gredell et al., 2004)

5. The lack of effect of finasteride on WT and ob/ob mice is not sufficient to make the statement that there is no endogenous basal neurosteroid-induced tone. Indeed, there is in fact an endogenous basal neurosteroid-induced tone as illustrated by the experiments with cyclodextrin. The lack of observed effect with finasteride is consistent with other authors (Brown, 2012 Thesis). The lack of effect with finasteride in this context is explained as follows: Finasteride inhibits the production of new neurosteroid via $5 a$-reductase inhibition. However it does not impact on the endogenous neurosteroid compounds that are already present within the slice preparation. This question was considered during the project and it was decided that the appropriate way to answer this question would be to inject finasteride in vivo, some hours/days prior to the in vitro experiments. The half-life of the neurosteroid Allopregnanolone is approximately 30 minutes (Mellon et al., 2008). However, a functional equilibrium typically exists between Allopregnanlone and its neurosteroid precursors which act as an immediate reservoir that would not be blocked instantly by finasteride, which inhibits $5 a \mathrm{R}$ rather than $3 \mathrm{a}-\mathrm{HSD}$ (Figure 1).

6. It is very interesting

7. Agreed. The rotarod test results for the ob/ob are included for completeness and for 
demonstrating the phenotype but have minimal validity other than that. The ob/ob rotarod experiments illustrate why the sedative effects of neurosteroid were studied in WT rather than the ob/ob. The ob/ob is type-2 diabetic because of obesity. Other obese mouse models such as the $\mathrm{db} / \mathrm{db}$ also have type-2 diabetes. There does not appear to be an obese mouse model without type-2 diabetes. Thus the respective impacts of obesity and type-2 diabetes on rotarod ability cannot be differentiated.

8. This is a potentially translatable finding.

9. It is known that general affinity for the GABAA receptor varies between different neurosteroid compounds. Separately, GABAA receptors expressing specific subunits have greater affinity for a given neurosteroid. Indeed, the following is an extract from my thesis:

'THIP is a low affinity partial agonist at receptors expressing the $g$ subunit (i.e. most GABA Rs), but has high affinity for $G_{A B A}$ Rs that express the a4b3d subunits where it behaves as a 'superagonist' compared to GABA (Brown et al., 2002; Farrant \& Nusser, 2005; KrogsgaardLarsen et al., 2004). d-GABA ${ }_{A} R s$ are predominantly located at extrasynaptic locations; therefore THIP is a useful pharmacological agent for the selective activation of tonic currents (Belelli et al., 2005; Farrant \& Nusser, 2005).' (Humble, 2013)

For reasons of brevity the issue of differential binding sites to neurosteroids was not explored significantly within the paper, but this was covered in substantial detail within my thesis (Humble, 2013). It is summarised in the Conclusions section of the thesis:

'Pipette-applied neurosteroids allopregnanolone and ganaxolone (but not DHP) were also able to prolong the decay time of cortical GABA $A_{A}$ mIPSCs in a differential manner. Allopregnanolone induced a greater effect than ganaxolone on GABA $A$ R mIPSC decay time, but there was no difference in the response to the respective drugs between the WT and $o b / o b$ mice. These findings suggest that neurosteroids are able to modulate the $G A B A_{A} R$ from the intracellular compartment and that the sensitivity of the $G A B A_{A} R$ is the same for WT and ob/ob mice. In addition, when indometacin was co-applied in the pipette with ganaxolone it had no impact on the efficacy of ganaxolone. This observation is inconsistent with the notion that indometacin competes with ganaxolone for its binding of the $G A B A_{A} R$.' (Humble, 2013)

10. This is an excellent point and is the subject of a Brief Communication that I have written on the subject of Mitochondrial dysfunction and neurosteroid synthesis in diabetic neuropathy that will be published shortly. I would be happy to refer to this further in the discussion.

Competing Interests: None to declare 
The benefits of publishing with F1000Research:

- Your article is published within days, with no editorial bias

- You can publish traditional articles, null/negative results, case reports, data notes and more

- The peer review process is transparent and collaborative

- Your article is indexed in PubMed after passing peer review

- Dedicated customer support at every stage

For pre-submission enquiries, contact research@f1000.com 